\title{
AAZTA5-squaramide ester: promising tool for 177Lu-labeling of monoclonal antibodies under mild conditions
}

\section{Benedikt Klasen}

Johannes Gutenberg Universität Mainz https://orcid.org/0000-0002-4433-0269

\section{Euy Sung Moon}

Johannes Gutenberg Universität Mainz

Frank Rösch ( $\nabla$ froesch@uni-mainz.de)

https://orcid.org/0000-0001-7472-4050

\section{Research article}

Keywords: AAZTA, AAZTA5, DOTA, Lutetium-177, 177Lu, Squaric Acid, Squaramide, Antibody,

Radioimmunotherapy

Posted Date: April 29th, 2020

DOl: https://doi.org/10.21203/rs.3.rs-23753/v1

License: (c) (1) This work is licensed under a Creative Commons Attribution 4.0 International License. Read Full License 


\section{Abstract \\ Background}

Combining the advantages of both cyclic and acyclic chelator systems, AAZTA (1,4-bis(carboxymethyl)-6[bis(carboxymethyl)]amino-6-methylperhydro-1,4-diazepine) is well suited for complexation of various diagnostic and therapeutic radiometals such as gallium- 68 , scandium- 44 and lutetium- 177 under mild conditions. Due to its specificity for primary amines and $\mathrm{pH}$ dependent binding properties, squaric acid (SA) represents an excellent tool for selective coupling of the appropriate chelator to different target vectors. Therefore, the aim of this study was to evaluate radiolabeling properties of the novel bifunctional AAZTA ${ }^{5}$-SA being coupled to a model antibody (bevacizumab) in comparison to DOTA-SA using the therapeutic nuclide lutetium-177.

\section{Results}

As proof-of-concept, bevacizumab was first functionalized with either AAZTA ${ }^{5}$-SA or DOTA-SA. After purification via fractionated size exclusion chromatography (SEC), the corresponding immunoconjugates were subsequently radiolabeled with lutetium- 177 at pH 7 and room temperature (RT) as well as $37^{\circ} \mathrm{C}$. After 90 min, labeling of AAZTA ${ }^{5}$-SA-mAb resulted in almost quantitative radiochemical yields (RCY) of > $98 \%$ and $>99 \%$, respectively. After purification via SEC, the radioconjugate [ ${ }^{177}$ Lu] Lu-AAZTA ${ }^{5}-$ SA-mAb could be obtained with a purity of $>99 \%$ and an apparent specific activity of $4.5 \mathrm{GBq} / \mu \mathrm{mol}$. In contrast, ${ }^{177}$ Lu-labeling of DOTA-SA-mAb showed negligible radiochemical yields of $<2 \%$ both at room temperature and $37^{\circ} \mathrm{C}$. In vitro complex stability measurements of $\left[{ }^{177} \mathrm{Lu}\right] \mathrm{Lu}-\mathrm{AAZTA}{ }^{5}-\mathrm{SA}-\mathrm{mAb}$ in human serum at $37{ }^{\circ} \mathrm{C}$ indicated $>99 \%$ protein bound activity within 15 days. In phosphate buffered saline (PBS), a slightly decreased stability of $>93 \%$ intact conjugate was observed over the same period.

\section{Conclusion}

Coupling of AAZTA ${ }^{5}$-SA to the monoclonal antibody bevacizumab allowed for ${ }^{177}$ Lu-labeling with almost quantitative radiochemical yields both at room temperature and $37^{\circ} \mathrm{C}$. Within 15 days, the resulting radioconjugate indicated very high in vitro complex stability both in human serum and PBS. Therefore, AAZTA ${ }^{5}$-SA is a promising tool for ${ }^{177}$ Lu-labeling of sensitive biomolecules such as antibodies for theranostic applications.

\section{Background}

The utilization of monoclonal antibodies (mAbs) or corresponding smaller protein fragments for immunotherapeutic strategies targeting cancer has gained increasing clinical importance and interest in recent years. Since the admission of the first antibody Muromonab-CD3 (Orthoclone OKT3) in 1986, more 
than 90 therapeutic monoclonal antibodies or antibody-based drugs have been approved by the Food and Drug Administration (FDA) or the European Medicines Agency (EMA), about 55 of them in the last five years and 32 of them aiming for treatment of cancer (Abramowicz et al. 1989; Cai 2018; Cai 2017; Cai 2016; Cai 2014; Kaplon et al. 2020; Kimiz-Gebologlu et al. 2018; Mullard 2019).

In addition to the native therapeutic anti-cancer effects of unmodified mAbs, their highly selective binding can also be used to transport either diagnostically or therapeutically relevant radionuclides to a specific target. An essential factor in the selection of a suitable radionuclide is its half-life, which should match to the typically slow pharmacokinetics of intact antibodies. Although the utilization of such radioimmunoconjugates for diagnosis and treatment of cancer and other diseases represents a promising strategy, to date there is only a small number of actually clinically approved agents including

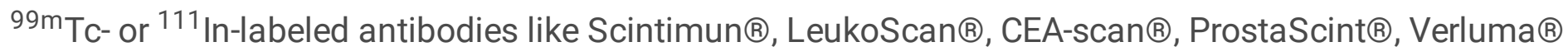
and OncoScint ${ }^{\circledR}$ for SPECT imaging as well as the ${ }^{131} \mathrm{I}$ - or ${ }^{90} \mathrm{Y}$-labeled conjugates Bexxar ${ }^{\circledR}$ and Zevalin $\AA$ for radioimmunotherapy (RIT) (Bohdiewicz 1998; Boswell and Brechbiel 2007; Breitz et al. 1997; Moffat et al. 1996; Quigley et al. 2008; Richter et al. 2011; Rizvi et al. 2015; Taneja 2004).

There are several therapeutic radionuclides that are used in combination with antibodies or being subject of recent investigations aiming for radioimmunotherapeutic applications including the $\beta^{-}$-emitters ${ }^{67} \mathrm{Cu}$, ${ }^{90} \mathrm{Y},{ }^{131} \mathrm{I}$ and ${ }^{177} \mathrm{Lu}$ and a-emitters ${ }^{213} \mathrm{Bi}$ and ${ }^{225} \mathrm{Ac}$ (Barbet et al. 2012; Kawashima 2014; Moek et al. 2017; Sharkey and Goldenberg 2011; Yeong et al. 2014). Since it could be shown that smaller tumors and metastases are more accessible for radiolabeled antibodies than large ones and thus show a better response to this treatment, RIT is a promising tool especially for therapy of cancer even before tumors or lesions become detectable via imaging methods or in advanced stages of metastatic diseases (Barbet et al. 2012; Barbet et al. 2009). In this case, $\beta^{-}$-emitting radionuclides with comparatively low $\beta^{-}$-energy are the best choice to minimize the damage to surrounding healthy tissue while destroying malignant cells in the target. Due to the fact that it can be directly covalently bound to the protein by iodination of tyrosine residues and due to its dual emission (maximum $\beta^{-}$-energy of $606 \mathrm{keV}$ and primary $\gamma$-energy of $364 \mathrm{keV}$ ), iodine-131 is a candidate of great interest for both RIT and SPECT-imaging (Boros and Holland 2018; Kawashima 2014; Yeong et al. 2014). However, it could be shown, that the covalent bond between tyrosine residues and iodine provides insufficient stability leading to certain release of free ${ }^{131} \mathrm{I}$ or other proteolytic products even in the case of internalizing antigens (Repetto-Llamazares et al. 2014; Stein et al. 2003). Another frequently used radionuclide for RIT is ${ }^{90} \mathrm{Y}$, which decays exclusively (100\%) via $\beta^{-}$emission. With a maximum electron energy of $2.288 \mathrm{MeV}$ this radiometal provides a comparatively long effective range and therefore the opportunity to penetrate larger solid tumors (Boros and Holland 2018). Compared to these isotopes, ${ }^{177} \mathrm{Lu}$ has several advantages regarding radioimmunotherapeutic applications for treatment of more accessible smaller tumors. In contrast to ${ }^{90} \mathrm{Y},{ }^{177} \mathrm{Lu}$ offers significantly lower beta-particle energies $\left(E_{\beta, \max }=498 \mathrm{keV}\right)$ and compared to ${ }^{131} \mathrm{I}$ also the absence of high-energy gamma photons (iodine-131: $E_{\gamma, \max }=723 \mathrm{keV}$; lutetium-177: $\mathrm{E}_{\gamma, \max }=208 \mathrm{keV}$ ). Furthermore, compared to ${ }^{90} \mathrm{Y}\left(\mathrm{t}_{1 / 2}=64.1 \mathrm{~h}\right)$, the physical half-life of ${ }^{177} \mathrm{Lu}\left(\mathrm{t}_{1 / 2}=6.7 \mathrm{~d}\right)$ matches better the slow pharmacokinetics 
of full-size antibodies and is shorter than that of ${ }^{131}{ }^{I}\left(t_{1 / 2}=8.0 \mathrm{~d}\right)$ (Barbet et al. 2012; Dash et al. 2015). Lutetium-177 therefore provides excellent properties both for RIT and immuno-SPECT-imaging of small solid tumors or metastatic lesions even at an early stage of the disease. A number of ${ }^{177}$ Lu-labeled radiopharmaceuticals such as the somatostatin analogues ${ }^{177}$ Lu-DOTATOC/DOTATATE have already demonstrated the great potential of ${ }^{177}$ Lu-based endoradiotherapy (Bodei et al. 2015; Demirci et al. 2018; Forrer et al. 2005; Kasi et al. 2019). Nevertheless, both radiometals ${ }^{90} \mathrm{Y}$ and ${ }^{177}$ Lu are typical candidates for mAb-based applications.

In recent years, several chelator scaffolds have been evaluated for the complexation of ${ }^{177} \mathrm{Lu}$ and ${ }^{90} \mathrm{Y}$ including linear systems like DTPA (Diethylenetriaminepentaacetic acid) and CHX-A"-DTPA (Cyclohexyldiethylenetriaminepentaacetic acid), as well as cyclic systems like DOTA $(1,4,7,10$ Tetraazacyclododecane-1,4,7,10-tetraacetic acid), TETA (1,4,8,11-Tetraazacyclotetradecane-1,4,8,11tetraacetic acid) and corresponding bifunctional derivatives (e.g. DOTAGA 1,4,7,10Tetraazacyclododececane-1-glutaric acid-4,7,10-triacetic acid), respectively (Boros and Holland 2018; Breeman et al. 2003; Hens et al. 2010; Kodama et al. 1991; Koppe et al. 2004; Milenic et al. 2002; Price and Orvig 2014; Stimmel and Kull 1998; Tóth and Brücher 1994). As one of the first ever used complexing agent in radiochemistry, DTPA (and its various bifunctional derivatives) provides fast incorporation kinetics at mild conditions in combination with a variety of radiometals (Blower et al. 1996; Camera et al. 1994; Koppe et al. 2004; Price and Orvig 2014). However, due to the acyclic structure, radiometal-DTPA complexes frequently show insufficient stability in vivo. To date, DOTA still represents one of the most important and most commonly used chelator systems for radiolabeling of a wide spectrum of molecules, especially of small molecule target vectors, with radiometals such as ${ }^{111} \mathrm{In},{ }^{86 / 90} \mathrm{Y}$, ${ }^{225} \mathrm{Ac},{ }^{44 / 47} \mathrm{Sc},{ }^{67 / 68} \mathrm{Ga}$ and ${ }^{177}$ Lu (Ballangrud et al. 2004; Breeman et al. 2003; Broan et al. 1991; Clarke and Martell 1991; Liu et al. 2002; Price and Orvig 2014; Stimmel et al. 1995). In most cases, DOTA complexes with trivalent radiometals are characterized by very high stability, even after long retention times in vivo. However, due to its macrocyclic structure, DOTA functionalized molecules typically require high temperatures up to $95^{\circ} \mathrm{C}$ for fast and successful radiolabeling with high radiochemical yields. Milder conditions usually lead to significantly reduced yields or to the necessity of much longer reaction times (up to hours) (Banerjee et al. 2015; Boros and Holland 2018). Endoradiotherapeutic applications for cancer treatment typically require high activities of ${ }^{177} \mathrm{Lu}$ up to 6-8 GBq per dose (Demirci et al. 2018; Forrer et al. 2005). To prevent or at least to reduce radiolytic degradation of important binding regions of an antibody at such high activity levels, the synthesis duration and the time between production and administration of the radiopharmaceutical needs to be minimized (Garrison 1987). Despite its advantages in kinetic and thermodynamic stability, DOTA therefore represents a rather inappropriate choice for radiolabeling of temperature-sensitive biomolecules such as antibodies. As a result, preclinical and clinical applications of ${ }^{177} \mathrm{Lu}$ - or ${ }^{90} \mathrm{Y}$-labeled mAbs are to date very limited due to either insufficient in vivo complex stability, poor radiochemical yields or very long reaction times at temperatures that maintain protein integrity. Though there are a few studies featuring DOTA-functionalized proteins (Fortin et al. 2007; Hermanto et al. 2016; Milenic et al. 2002; Orlova et al. 2013; Perk et al. 2005; Rasaneh et al. 2010; Thakral et al. 2014; 
Wojdowska et al. 2015), there is a great demand for suitable bifunctional chelator molecules, which ensure both rapid and complete radiolabeling at low temperatures as well as high complex stability.

A further chelator system that has recently shown very promising results regarding the complexation of scandium, gallium and copper as well as lutetium and other lanthanides is AAZTA (1,4-

Bis(carboxymethyl)-6-[bis(carboxymethyl)]amino-6-methylperhydro-1,4-diazepine; Fig. 1) (Baranyai et al. 2009; Greifenstein et al. 2020; Lattuada et al. 2011; Nagy et al. 2017; Pfister et al. 2015; Price and Orvig 2014; Sinnes et al. 2019). It was first introduced in 2004 by Aime et al. as a novel molecule that forms stable complexes with $\mathrm{Gd}(\mathrm{III})$ as an innovative MRI contrast agent (Aime et al. 2004). AAZTA consists of a 1,4-diazepane scaffold bearing one additional exocyclic nitrogen in 6-position. The three heteroatoms are functionalized with a total of four carboxylic acid groups leading to 7 donors of a $\mathrm{N}_{3} \mathrm{O}_{4}$ coordination structure. It therefore combines the advantages of both linear and macrocyclic structures in one molecule providing fast complexation kinetics under mild conditions, high yields and promising complex stabilities (Waldron et al. 2013). Due to these excellent properties, AAZTA represents a promising tool for radiolabeling of monoclonal antibodies with ${ }^{177}$ Lu for RIT. Since 2008 , various approaches have been pursued to develop bifunctional derivatives with different functional groups including hydroxides, amines, and carboxylic acids (Lattuada et al. 2011). In 2012 Manzoni et al. introduced AAZTA ${ }^{5}$ (1,4Bis(carboxymethyl)-6-[bis(carboxymethyl)]amino-6-[pentanoic-acid]perhydro-1,4-diazepine) as a derivative containing an additional carboxylic acid group spaced by four methylene entities (Fig. 1) (Manzoni et al. 2012).

In this study we wanted to evaluate the applicability of AAZTA ${ }^{5}$ for radiolabeling of antibodies with ${ }^{177} \mathrm{Lu}$ regarding radioimmunotherapy compared to DOTA as the gold standard for complexation of this radiometal. For this purpose, we first synthesized AAZTA ${ }^{5}$ as recently reported by our group and extended the basic scaffold with an ethylenediamine unit (Sinnes et al. 2019). In the next step, we introduced a squaric acid diethyl ester $\left(\mathrm{SA}(\mathrm{OEt})_{2}\right)$ as linker entity via selective formation of a vinylogous monoamide (Fig. 1). SA(OEt) ${ }_{2}$ provides various excellent properties for coupling of an appropriate chelator to different target vectors. On the one hand, it reacts selectively with primary amines which often avoids the necessity of protective group strategies and therefore simplifies the synthesis of the tracer or corresponding precursor. On the other hand, it offers the possibility of a stepwise asymmetric and $\mathrm{pH}$ dependent amidation. In a first step, squaric acid diethyl ester can be coupled to the amine of a chelator moiety at $\mathrm{pH} 7$ via monoamide formation and subsequently be isolated and stored. In a second step the resulting precursor can then be coupled at $\mathrm{pH} 9$ to the primary amine of appropriate target vectors such as antibodies. This unique property is based on a change of aromaticity during the first reaction step (Tietze et al. 1991; Wurm and Klok 2013). Despite its advantages, the utilization of squaric acid as linker entity in radiopharmaceutical chemistry is still mostly uncommon and innovative. 2016, Rudd et al. introduced a deferoxamine squaramide ester for radiolabeling of mAbs with ${ }^{89} \mathrm{Zr}$ for Immuno-PET imaging. They were also able to show the effect of increasing ${ }^{89} \mathrm{Zr}$-deferoxamine-complex stability due to the two additional oxygen atoms of the squaramide moiety leading to an octadentate coordination geometry (Rudd et al. 2016). 
As proof of concept we used the commercially available monoclonal antibody bevacizumab (trade name Avastin $\left.{ }^{\circledR}\right)$ which is applied for treatment of various types of cancer inhibiting the vascular endothelial growth factor A (VEGF-A). Yet it was not our intention to refer to the pharmacology of bevacizumab, in our experiments it simply served as biomolecule with $\mathrm{mAb}$ profile. First, the protein was functionalized with AAZTA ${ }^{5}$-SA. Following optimized purification, the resulting conjugate was subsequently radiolabeled with ${ }^{177}$ Lu under mild conditions. For comparison, we analogously synthesized, purified and radiolabeled DOTA-SA-bevacizumab. Prior to evaluation of the corresponding immunoconjugates, the unconjugated bifunctional chelators DOTA-SA and AAZTA ${ }^{5}$-SA were also radiolabeled and compared under the same conditions.

\section{Materials And Methods}

\section{General}

All chemicals were purchased from Sigma-Aldrich, Merck, VWR, TCl, Acros Organics, Fluka, AlfaAesar, Fisher Scientific and Chematech and used without further purification unless otherwise declared. For radiolabeling reactions trace metal-free substances were used. Column chromatography was performed using silica gel 60 (0.063-0.200 mm, Acros Organics) as stationary phase and the respectively specified solvents as mobile phase. NMR measurements were performed using a Bruker Avance III HD 400 $(400 \mathrm{MHz})$ or Avance III 600 (600 MHz). Mass spectrometry was measured via Agilent Technologies 1220 Infinity LC system coupled to an Agilent Technologies 6130 Single Quadrupole LC/MS system. HPLC purification and analysis was performed using a Merck LaChrom system with Hitachi L7100 pump and L7400 UV-detector and the respectively mentioned column and conditions. Purification of the immunoconjugates was performed via fractionated SEC using PD-10 Desalting Columns (8.3 mL Sephadex ${ }^{\mathrm{TM}}$ G-25, GE Healthcare) and PBS as mobile phase. For radiolabeling experiments n.c.a. [ $\left.{ }^{177} \mathrm{Lu}\right] \mathrm{LuCl}_{3}$ in $0.04 \mathrm{M} \mathrm{HCl}$ (ITG, Garching, Germany) was used. Radioactivity of the samples was measured using a PC-based dose calibrator (ISOMED 2010, Nuklear Medizintechnik Dresden GmbH). Radiochemical yields were determined via radio thin layer chromatography (radio-TLC, stationary phase: Merck Silica $60 \mathrm{~F}_{254}$ TLC plates; mobile phase: $0.1 \mathrm{M}$ citrate-buffer $\mathrm{pH}$ 4), image plate scanner (CR35-Bio, Elysia Raytest) and AIDA Image Analysis software (Elysia Raytest). Radiochemical purity was measured via radio-TLC and radio-SEC-HPLC monitoring (column: Phenomenex BioSep SEC-S 2000, mobile phase: $0.05 \mathrm{M}$ sodium phosphate $\mathrm{pH}$ 7, flow: $1 \mathrm{~mL} / \mathrm{min}$ ).

\section{Organic Synthesis}

\section{Synthesis of AAZTA ${ }^{5}-S A$}

1,4-Dibenzyl-6-methylpentanoate-6-nitroperhydro-1,4-diazepine (1) 
A mixture of 2-nitrocyclohexanone $(2.00 \mathrm{~g}, 13.9 \mathrm{mmol})$, Amberlyst ${ }^{\circledR}$ A21 $(1.05 \mathrm{~g})$ and abs. methanol $(35 \mathrm{~mL})$ was stirred at $60^{\circ} \mathrm{C}$ under reflux for 1 hour. $N, N^{\prime}$-Dibenzylethylenediamine $(3.36 \mathrm{~g}, 13.9 \mathrm{mmol})$ and paraformaldehyde $(1.67 \mathrm{~g}, 55.5 \mathrm{mmol})$ were added to the solution. The resulting suspension was heated to $80^{\circ} \mathrm{C}$ and stirred overnight. After completion of the reaction, the mixture was filtered and the filtrate was evaporated under reduced pressure. After purification via column chromatography (cyclohexane/ethylacetate 9:1, $\left.\mathrm{R}_{\mathrm{f}}=0.27\right)$ product 1 was obtained as yellow oil $(5.20 \mathrm{~g}, 11.8 \mathrm{mmol}, 85 \%)$. ${ }^{1} \mathrm{H}-\mathrm{NMR}\left(\mathrm{CDCl}_{3}, 400 \mathrm{MHz}, \delta\right.$ [ppm]): $7.29(\mathrm{~m}, 10 \mathrm{H}) ; 3.66(\mathrm{~s}, 3 \mathrm{H}) ; 3.67$ (dd, J = $\left.13.5 \mathrm{~Hz}, 4 \mathrm{H}\right) ; 3.25$ (dd, J = $14.0 \mathrm{~Hz}, 4 \mathrm{H}) ; 2.63(\mathrm{~m}, 4 \mathrm{H}) ; 2.12(\mathrm{~m}, 2 \mathrm{H}) ; 1.59(\mathrm{~m}, 2 \mathrm{H}) ; 1.32(\mathrm{~m}, 2 \mathrm{H}) ; 0.78(\mathrm{~m}, 2 \mathrm{H}) .{ }^{13} \mathrm{C}-\mathrm{NMR}\left(\mathrm{CDCl}_{3}\right.$, $100 \mathrm{MHz}, \delta$ [ppm]): 173.6 (s); 139.1 (s); 129.1 (s); 128.3 (s); 127.3 (s); 94.8 (s); 64.9 (s); 61.8 (s); 58.9 (s); $51.5(\mathrm{~s}) ; 36.5(\mathrm{~s}) ; 33.6(\mathrm{~s}) ; 24.6$ (s); 22.6 (s). $\mathrm{MS} \mathrm{ESI}^{+}(\mathrm{m} / \mathrm{z})$ : found $440.3\left[\mathrm{M}+\mathrm{H}^{+}\right]$, calculated for $\mathrm{C}_{25} \mathrm{H}_{33} \mathrm{~N}_{3} \mathrm{O}_{4}: 439.25$

\section{1,4-Di(tert-butylacetate)-6-methylpentanoate-6-amino-di(tert-butylacetate)-perhydro-1,4-diazepine (3)}

To a mixture of $1(1.05 \mathrm{~g}, 2.39 \mathrm{mmol})$ and $\mathrm{Pd}(\mathrm{OH})_{2} / \mathrm{C}(0.62 \mathrm{~g}, 10 \mathrm{wt} \%)$ in abs. ethanol $(20 \mathrm{~mL})$ acetic acid $(411 \mu \mathrm{L}, 7.19 \mathrm{mmol})$ was added and the resulting solution was stirred at room temperature overnight under an atmosphere of hydrogen. After completion of the reaction, the mixture was filtered over Celite $\circledast$ and the filtrate was evaporated under reduced pressure. The crude product 2 was used for the following reaction without further purification.

To a solution of $2(2.39 \mathrm{mmol})$ and $\mathrm{K}_{2} \mathrm{CO}_{3}(1.32 \mathrm{~g}, 9.57 \mathrm{mmol})$ in abs. acetonitrile $(30 \mathrm{~mL})$ tert-butyl bromoacetate $(1.41 \mathrm{~mL}, 9.57 \mathrm{mmol})$ and sodium iodide $(0.80 \mathrm{~g}, 4.82 \mathrm{mmol})$ were added. The resulting mixture was stirred overnight at $40{ }^{\circ} \mathrm{C}$. After completion of the reaction, the solvent was evaporated under reduced pressure. The residue was subsequently purified via column chromatography (cyclohexane/ethylacetate 7:1, $\left.R_{\mathrm{f}}=0.15\right)$ to yield product 3 as yellow oil $(0.89 \mathrm{~g}, 1.30 \mathrm{mmol}, 54 \%) .{ }^{1} \mathrm{H}$ -

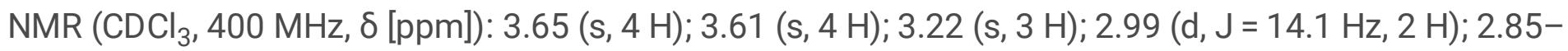
2.65 (m, 4 H); 2.63 (d, J = 14.1 Hz, 2 H); 2.31 (t, J = 7.4 Hz, 2 H); 1.62-1.52 (m, 4 H); 1.44 (s, 18 H); 1.43 (s, $18 \mathrm{H}) ; 1.25$ (m, $2 \mathrm{H}$ ). ${ }^{13} \mathrm{C}-\mathrm{NMR}\left(\mathrm{CDCl}_{3}, 100 \mathrm{MHz}, \delta\right.$ [ppm]): 174.4 (s); 172.9 (s); 170.9 (s); 80.9 (s); 80.4 (s); 65.3 (s); 63.2 (s); 62.6 (s); 59.4 (s); 52.1 (s); 51.6 (s); 37.3 (s); 34.3 (s); 28.3 (s); 28.3 (s); 25.9 (s); 21.8 (s). $\mathrm{MS} \mathrm{ESI}^{+}(\mathrm{m} / \mathrm{z})$ : found $686.5\left[\mathrm{M}+\mathrm{H}^{+}\right], 708.4\left[\mathrm{M}+\mathrm{Na}^{+}\right]$, calculated for $\mathrm{C}_{35} \mathrm{H}_{63} \mathrm{~N}_{3} \mathrm{O}_{10}: 685.45$

\section{1,4-Di(tert-butylacetate)-6-pentanoic acid-6-(amino-di(tert-butylacetate))-perhydro-1,4-diazepine (4)}

To a solution of $3(172 \mathrm{mg}, 0.25 \mathrm{mmol})$ in 1,4-dioxane/water $(2: 1,3 \mathrm{~mL})$ a $1 \mathrm{M}$ solution of LiOH $(375 \mu \mathrm{L}$, $0.38 \mathrm{mmol}$ ) was added and the resulting mixture was stirred overnight at room temperature. After completion of the reaction the solvent was evaporated under reduced pressure and $1 \mathrm{M} \mathrm{NaHCO}_{3}(10 \mathrm{~mL})$ was added to the residue. The mixture was extracted with chloroform $(5 \times 5 \mathrm{~mL})$ and the combined organic extracts were washed with water, dried over $\mathrm{Mg}_{2} \mathrm{SO}_{4}$ and evaporated under reduced pressure. Product 4 was obtained as yellow oil without further purification ( $116 \mathrm{mg}, 0.17 \mathrm{mmol}, 69 \%)$. ${ }^{1} \mathrm{H}-\mathrm{NMR}$ $\left(\mathrm{CDCl}_{3}, 400 \mathrm{MHz}, \delta[\mathrm{ppm}]\right): 3.60$ (s, $\left.4 \mathrm{H}\right) ; 3.23$ (s, $\left.4 \mathrm{H}\right) ; 3.00-2.97$ (d, J = 14.1 Hz, $\left.2 \mathrm{H}\right) ; 2.88-2.60$ (m, $\left.6 \mathrm{H}\right)$; 
2.36-2.32 (t, J = 7.9 Hz, $2 \mathrm{H}) ; 1.64-1.52(\mathrm{~m}, 4 \mathrm{H}) ; 1.43(\mathrm{~s}, 18 \mathrm{H}) ; 1.42(\mathrm{~s}, 18 \mathrm{H}) ; 1.24(\mathrm{~m}, 2 \mathrm{H}) .{ }^{13} \mathrm{C}-\mathrm{NMR}$ ( $\mathrm{CDCl}_{3}, 100 \mathrm{MHz}, \delta$ [ppm]): 178.9 (s); 172.9 (s); 170.9 (s); 81.0 (s); 80.5 (s); 65.1 (s); 63.1 (s); 59.4 (s); 52.2 (s); 34.2 (s); 29.8 (s); 28.3 (s); 28.2 (s); 25.6 (s); 22.8 (s); 21.9. MS ESI+ (m/z): found 672.4 [M + H $\left.\mathrm{H}^{+}\right], 694.5$ $\left[\mathrm{M}+\mathrm{Na}^{+}\right]$, calculated for $\mathrm{C}_{34} \mathrm{H}_{61} \mathrm{~N}_{3} \mathrm{O}_{10}: 671.44$

1,4-Di(tert-butylacetate)-6-((5-(2-((2-ethoxy-3,4-dioxocyclobut-1-en-1yl)aminoethyl)amino)-5-oxopentyl)-6(amino-di(tert-butylacetate))-perhydro-1,4-diazepine (5)

To a solution of 4 (75 mg, $0.11 \mathrm{mmol})$ in abs. acetonitrile $(1 \mathrm{~mL}) \mathrm{HBTU}(42 \mathrm{mg}, 0.11 \mathrm{mmol}), \mathrm{HOBt}(45 \mathrm{mg}$, $0.33 \mathrm{mmol})$ and DIPEA $(58 \mu \mathrm{L}, 0.33 \mathrm{mmol})$ were added and the resulting mixture was stirred for $1 \mathrm{~h}$ at room temperature. $N$-Boc-1,2-diaminoethane $(35 \mu \mathrm{L}, 0.22 \mathrm{mmol})$ was added and stirring was continued overnight. After completion of the reaction, the solvent was evaporated under reduced pressure and the residue was purified via column chromatography (cyclohexane/ethylacetate $1: 1, R_{f}=0.13$ ). Product 5 was obtained as yellow oil (74.2 mg, $91 \mu \mathrm{mol}, 82 \%) .{ }^{1} \mathrm{H}-\mathrm{NMR}$ (DMSO, $\left.400 \mathrm{MHz}, \delta[\mathrm{ppm}]\right): 6.34(\mathrm{br}, 1 \mathrm{H})$; $5.26(\mathrm{br}, 1 \mathrm{H}) ; 3.60(\mathrm{~s}, 4 \mathrm{H}) ; 3.38-3.34(\mathrm{~m}, 2 \mathrm{H}) ; 3.26-3.24(\mathrm{~m}, 2 \mathrm{H}) ; 3.21(\mathrm{~s}, 4 \mathrm{H}) ; 2.96(\mathrm{~d}, \mathrm{~J}=14.1 \mathrm{~Hz}, 2 \mathrm{H})$; 2.75-2.73 (m, $2 \mathrm{H}) ; 2.66-2.63(\mathrm{~m}, 2 \mathrm{H}) ; 2.59(\mathrm{~d}, \mathrm{~J}=14.1 \mathrm{~Hz}, 2 \mathrm{H}) ; 2.19(\mathrm{t}, 2 \mathrm{H}) ; 1.62-1.53(\mathrm{~m}, 4 \mathrm{H}) ; 1.43(\mathrm{~s}$, $18 \mathrm{H}) ; 1.42$ (s, $27 \mathrm{H}) ; 1.28-1.20$ (m, $2 \mathrm{H}) .{ }^{13} \mathrm{C}-\mathrm{NMR}\left(\mathrm{CDCl}_{3}, 100 \mathrm{MHz}, \delta[\mathrm{ppm}]\right): 174.4$ (s); 173.3 (s); 172.8 (s); 165.9 (s); 82.9 (s); 82.8 (s); 63.4 (s); 62.5 (s); 62.1 (s); 55.5 (s); 54.5 (s); 47.1 (s); 40.8 (s); 39.9 (s); 35.6 (s); 29.8 (s); 28.5 (s); 28.3 (s); 28.1 (s); 27.9 (s); 26.2 (s); 23.4 (s). MS ESI (m/z): found 814.6 [M + H+ $836.5\left[\mathrm{M}+\mathrm{Na}^{+}\right]$, calculated for $\mathrm{C}_{41} \mathrm{H}_{75} \mathrm{~N}_{5} \mathrm{O}_{11}: 813.55$

1,4-Di(acetate)-6-((5-(2-((2-ethoxy-3,4-dioxocyclobut-1-en-1yl)-aminoethyl)amino)-5-oxopentyl)-6-(aminodi(acetate))-perhydro-1,4-diazepine (6)

A solution of $5(74.2 \mathrm{mg}, 91 \mu \mathrm{mol})$ in dichloromethane/trifluoroacetic acid $(1: 1,2 \mathrm{~mL})$ was stirred for $3 \mathrm{~h}$ at room temperature. After complete deprotection, the solvent was evaporated under reduced pressure and the residue was dissolved in $0.5 \mathrm{M}$ phosphate buffer $(\mathrm{pH}=7,4 \mathrm{~mL})$. To the resulting solution 3,4diethoxycyclobut-3-ene-1,2-dione (39 $\mu \mathrm{L}, 264 \mu \mathrm{mol})$ was added. The $\mathrm{pH}$ was adjusted to 7 with $1 \mathrm{M} \mathrm{NaOH}$ solution before stirring overnight at room temperature. After completion of the reaction, the product was purified via HPLC (column: Phenomenex Luna C18 semipreparative $(250 \times 10 \mathrm{~mm}) 10 \mu$, flow rate: $\left.5 \mathrm{~mL} / \mathrm{min}, 10 \% \mathrm{MeCN}+0.1 \% \mathrm{TFA}, \mathrm{t}_{\mathrm{R}}=12.5 \mathrm{~min}\right)$ yielding 6 as colorless solid $(16.2 \mathrm{mg}, 26 \mu \mathrm{mol}, 29 \%) .{ }^{1} \mathrm{H}-$ $\operatorname{NMR}\left(\mathrm{D}_{2} \mathrm{O}, 400 \mathrm{MHz}, \delta[\mathrm{ppm}]\right): 4.75-4.67(\mathrm{~m}, 2 \mathrm{H}) ; 3.88(\mathrm{~s}, 2 \mathrm{H}) ; 3.76-3.66(\mathrm{~m}, 8 \mathrm{H}) ; 3.59-3.44(\mathrm{~m}, 8 \mathrm{H})$; 3.40-3.38 (m, $2 \mathrm{H}) ; 2.20(\mathrm{t}, 2 \mathrm{H}) ; 1.52-1.45(\mathrm{~m}, 4 \mathrm{H}) ; 1.43(\mathrm{t}, 3 \mathrm{H}) ; 1.30-1.21(\mathrm{~m} ; 2 \mathrm{H}) .{ }^{13} \mathrm{C}-\mathrm{NMR}\left(\mathrm{D}_{2} \mathrm{O}\right.$, $100 \mathrm{MHz}, \delta$ [ppm]): 176.60 (s); 176.06 (s); 175.97 (s); 173.82 (s); 170.67 (s); 70.70 (s); 70.55 (s); 62.81 (s); 59.41 (s); 58.63 (s); 52.59 (s); 52.20 (s); 43.93 (s); 39.56 (s); 39.24 (s); 35.31 (s); 33.76 (s); 25.73 (s); 22.26 (s); 15.07 (s). MS ESI ${ }^{+}(\mathrm{m} / \mathrm{z})$ : found $614.3\left[\mathrm{M}+\mathrm{H}^{+}\right], 636.3\left[\mathrm{M}+\mathrm{Na}^{+}\right]$, calculated for $\mathrm{C}_{26} \mathrm{H}_{39} \mathrm{~N}_{5} \mathrm{O}_{12}: 613.26$

\section{Synthesis Of DOTA-SA}


A solution of tri-tert-butyl 2,2',2"-(10-(2-((2-aminoethyl)amino)-2-oxoethyl)-1,4,7,10-tetraazacyclododecane-1,4,7-triyl)triacetate (50 mg, $81 \mu \mathrm{mol})$ in dichloromethane/trifluoroacetic acid (1:1, 200 $\mu \mathrm{L})$ was stirred overnight at room temperature. After complete deprotection the solvent was evaporated under reduced pressure and the residue was dissolved in $0.5 \mathrm{M}$ phosphate buffer $(\mathrm{pH}=7,1 \mathrm{~mL})$. The $\mathrm{pH}$ was adjusted to 7 with $1 \mathrm{M} \mathrm{NaOH}$ solution. 3,4-diethoxycyclobut-3-ene-1,2-dione ( $36 \mu \mathrm{L}, 244 \mu \mathrm{mol}$ ) was added and the resulting mixture was stirred overnight at room temperature. After completion of the reaction the product was purified via HPLC (column: Phenomenex Luna C18 semipreparative $(250 \times 10 \mathrm{~mm}) 10 \mu$, flow rate: $5 \mathrm{~mL} / \mathrm{min}, 6 \%$ to $8 \% \mathrm{MeCN}+0.1 \%$ TFA in $20 \mathrm{~min}, \mathrm{t}_{\mathrm{R}}=9.5 \mathrm{~min}$ ) yielding 7 as colorless solid ( $19.1 \mathrm{mg}$, $34 \mu \mathrm{mol}, 41 \%) .{ }^{1} \mathrm{H}-\mathrm{NMR}\left(\mathrm{D}_{2} \mathrm{O}, 600 \mathrm{MHz}, \delta[\mathrm{ppm}]\right): 4.64-4.53$ (dq, $\left.2 \mathrm{H}\right) ; 3.93-2.89(\mathrm{~m}, 28 \mathrm{H}) ; 1.41-1.33$ (m, $3 \mathrm{H}) . \mathrm{MS} \mathrm{ESI}^{+}(\mathrm{m} / \mathrm{z})$ : found $571.3\left[\mathrm{M}+\mathrm{H}^{+}\right], 593.3\left[\mathrm{M}+\mathrm{Na}^{+}\right]$, calculated for $\mathrm{C}_{24} \mathrm{H}_{38} \mathrm{~N}_{6} \mathrm{O}_{10}: 570.26$

\section{Antibody Coupling And Radiolabeling With ${ }^{177} \mathrm{Lu}$}

\section{Synthesis and purification of AAZTA $A^{5}$-SA-bevacizumab}

20-120 $\mathrm{\mu L}$ of the bevacizumab solution (0.5-3.0 mg mAb, 3.4-20.1 nmol, $25 \mathrm{mg} / \mathrm{mL}$, Avastin ${ }^{\circledR}$, Roche) was diluted with $0.5 \mathrm{M} \mathrm{Na}_{2} \mathrm{HPO}_{4}$-buffer $(\mathrm{pH}=9,1 \mathrm{~mL})$. A tenfold molar excess of AAZTA ${ }^{5}$-SA solution (21-123 $\mu \mathrm{L}, 33.6-201.3 \mathrm{nmol}, 1 \mathrm{mg} / \mathrm{mL}$ ) was added and the mixture was shaken overnight at room temperature via thermomixer. The resulting immunoconjugate was subsequently purified via fractionated SEC. In detail, the PD-10 column was first preconditioned with $20 \mathrm{~mL}$ PBS. The reaction mixture was then completely applied to the column and the flow-through was collected in the first fraction. Subsequently, a further 9 fractions of $0.5 \mathrm{~mL}$ PBS each were collected. In the first approach ( $3 \mathrm{mg}$ initial amount of mAb), the protein containing fractions 6-8 were combined and homogenized before subsequent radiolabeling. In the second approach ( $0.5 \mathrm{mg}$ initial amount of $\mathrm{mAb}$ ), fractions 5 to 10 were used separately and radiolabeled individually. In the third approach ( $3.0 \mathrm{mg}$ initial amount of mAb), fraction 6 was used separately for subsequent radiolabeling and fraction 7 was further purified via second SEC using the same procedure. The sixth and seventh fraction of the extended purification step were combined and homogenized before radiolabeling.

\section{Determination of the chelator-to-antibody ratio (CAR) of AAZTA ${ }^{5}$-SA-bevacizumab}

AAZTA 5 -SA-bevacizumab in PBS (450 $\mu \mathrm{L}, 96.6-125.9 \mu \mathrm{g}$ protein, $0.65-0.84 \mathrm{nmol})$ was added to a solution of a known molar excess of [ $\left.{ }^{\mathrm{nat}} \mathrm{Lu}\right] \mathrm{LuCl}_{3} \times 6 \mathrm{H}_{2} \mathrm{O}$ (2.5-10 nmol, 3.0-15.4 eq.) spiked with $1 \mathrm{MBq}$ $\left[{ }^{177} \mathrm{Lu}\right] \mathrm{LuCl}_{3}$ in $550 \mu \mathrm{L} 0.5 \mathrm{M} \mathrm{HEPES}$ buffer $(\mathrm{pH} 7)$. The resulting mixture $(1 \mathrm{~mL})$ was shaken for $90 \mathrm{~min}$ at 
room temperature and $550 \mathrm{rpm}$ via thermomixer. After completion of the reaction the percentage of protein-bound activity was determined via radio-TLC. The chelator-to-antibody ratio was calculated via:

$\mathrm{CAR}=\% \mathrm{RCY}($ protein-bound activity $) \cdot \frac{\mathrm{n}\left(\left[{ }^{\mathrm{nat}} \mathrm{Lu}\right] \mathrm{LuCl}_{3}\right)}{\mathrm{n}\left(\mathrm{AAZTA} \mathrm{S}^{5}-\mathrm{SA}-\mathrm{mAb}\right)}$

\section{Synthesis and purification of DOTA-SA-bevacizumab}

$120 \mu \mathrm{L}$ of the bevacizumab solution (3.0 mg mAb, $20.1 \mathrm{nmol}, 25 \mathrm{mg} / \mathrm{mL}$, Avastin $囚$, Roche) was diluted with $0.5 \mathrm{M} \mathrm{Na}_{2} \mathrm{HPO}_{4}$-buffer $(\mathrm{pH}=9,1 \mathrm{~mL})$. A tenfold molar excess of DOTA-SA solution $(115 \mu \mathrm{L}$, $201.3 \mathrm{nmol}, 1 \mathrm{mg} / \mathrm{mL}$ ) was added and the mixture was shaken overnight at room temperature via thermomixer. The resulting immunoconjugate was subsequently purified via fractionated SEC using a PD10 Desalting Column (8.3 mL Sephadex ${ }^{\mathrm{TM}} \mathrm{G}-25$, GE Healthcare) and PBS as mobile phase. In detail, the column was first preconditioned with $20 \mathrm{~mL}$ PBS. The reaction mixture was then completely applied to the column and the flow-through was collected in the first fraction. Subsequently, a further 9 fractions with $0.5 \mathrm{~mL}$ PBS each were collected. In the first approach, the protein containing fractions $6-8$ were combined and homogenized before subsequent radiolabeling. In a further approach, fraction 6 was used separately for subsequent radiolabeling and fraction 7 was further purified via second SEC using the same procedure. The sixth and seventh fraction of the extended purification step were combined and homogenized before radiolabeling.

\section{Radiolabeling of AAZTA ${ }^{5}-S A$ with ${ }^{177} \mathrm{Lu}$}

$\left[{ }^{177} \mathrm{Lu}\right] \mathrm{LuCl}_{3}(48 \mathrm{MBq}$ in $25 \mu \mathrm{L} 0.04 \mathrm{M} \mathrm{HCl})$ was diluted with $525 \mu \mathrm{L} 0.5 \mathrm{M}$ HEPES-buffer $(\mathrm{pH} 7)$ and a solution of $10 \mathrm{nmol}$ AAZTA ${ }^{5}$-SA in PBS $(450 \mu \mathrm{L})$ was added subsequently. The resulting mixture $(1 \mathrm{~mL})$ was shaken for $30 \mathrm{~min}$ at $550 \mathrm{rpm}$ and either at room temperature or $37^{\circ} \mathrm{C}$ via thermomixer. Radiolabeling efficiency was investigated at different times via radio-TLC.

\section{Radiolabeling of DOTA-SA with ${ }^{177} \mathrm{Lu}$}

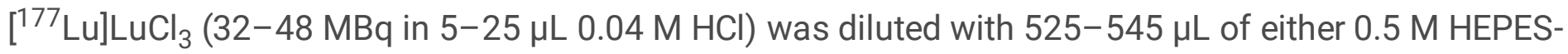
buffer ( $\mathrm{pH} 7$ ) or $1 \mathrm{M}$ ammonium acetate buffer (pH 5.5) and a solution of $10 \mathrm{nmol} 10 \mathrm{nmol}$ DOTA-SA in PBS $(450 \mu \mathrm{L})$ was added subsequently. The resulting mixture $(1 \mathrm{~mL})$ was shaken for $30-60 \mathrm{~min}$ at $550 \mathrm{rpm}$ and various temperatures $\left(\mathrm{RT}, 37^{\circ} \mathrm{C}, 50^{\circ} \mathrm{C}, 70^{\circ} \mathrm{C}, 95^{\circ} \mathrm{C}\right)$ via thermomixer. Radiolabeling efficiency was investigated at different times via radio-TLC.

\section{Radiolabeling of AAZTA5-SA-bevacizumab and DOTA-SA- bevacizumab with ${ }^{177} \mathrm{Lu}$ and purification of $\left[{ }^{177} \mathrm{Lu}\right] \mathrm{Lu}-$ AAZTA ${ }^{5}$-SA-bevacizumab}


[777 $\left.{ }^{17 u}\right] \mathrm{LuCl}_{3}(44-55 \mathrm{MBq}$ in 14-50 $\mu \mathrm{L} 0.04 \mathrm{M} \mathrm{HCl})$ was diluted with $0.5 \mathrm{M} \mathrm{HEPES}$-buffer $(\mathrm{pH} 7)$ to a total volume of $550 \mu \mathrm{L}$. Afterwards a solution of either AAZTA 5 -SA-bevacizumab (125-900 $\mu \mathrm{g}, 0.8-6.0 \mathrm{nmol})$ or DOTA-SA-bevacizumab $(272-900 \mu \mathrm{g}, 1.8-6.0 \mathrm{nmol})$ in PBS $(450 \mu \mathrm{L})$ was added and the mixture $(1 \mathrm{~mL})$ was shaken for $60-90 \mathrm{~min}$ at $550 \mathrm{rpm}$ and either at room temperature or $37^{\circ} \mathrm{C}$ via thermomixer. Radiolabeling efficiency was investigated at different times via radio-TLC and radio-SEC-HPLC. The resulting radioimmunoconjugate [ ${ }^{177}$ Lu] Lu-AAZTA ${ }^{5}$-SA-bevacizumab was subsequently purified via fractionated SEC using the same conditions as for purification prior to radiolabeling. The fractions containing the radiolabeled antibody were identified by measurement of radioactivity and radiochemical purity was determined via radio-TLC and radio-SEC-HPLC before combination and homogenization.

\section{Determination of in vitro complex stability of [ ${ }^{177}$ Lu]Lu-AAZTA ${ }^{5}$-SA-bevacizumab}

The purified radioimmunoconjugate [ ${ }^{177}$ Lu]Lu-AAZTA ${ }^{5}$-SA-bevacizumab (in $220 \mu \mathrm{L}$ PBS) was added to either $500 \mu \mathrm{L}$ human serum or $500 \mu \mathrm{L}$ PBS and the resulting mixtures were shaken via thermomixer at $37^{\circ} \mathrm{C}$ and $550 \mathrm{rpm}$ for $15 \mathrm{~d}$. The proportion of the intact conjugate versus released radionuclide was determined via radio-TLC at various times.

\section{Results And Discussion}

\section{Organic Synthesis}

The tert-butyl-protected derivative of AAZTA ${ }^{5}$ (4, Fig. class="InternalRef">2) could be successfully synthesized with an overall yield of $32 \%$ within four steps according to the work recently published by our group (Sinnes et al. 2019). The initial step first includes an in situ ring-opening reaction of 2nitrocyclohexane followed by formation of the diazepane scaffold via double Nitro-Mannich reaction of the resulting nucleophilic compound with $N, N$-dibenzylethylenediamine and paraformaldehyde. In the next step the endocyclic amines were deprotected by hydrogenolysis and the nitro group was simultaneously reduced to an exocyclic amine. Without further purification, intermediate 2 was then directly processed with tert-butyl bromoacetate to yield the tetra alkylated product $\mathbf{3}$. In order to obtain a free linkable carboxylic acid group, the corresponding methyl ester was finally cleaved with lithium hydroxide leading to the desired $\mathrm{AAZTA}^{5}\left({ }^{\mathrm{t}} \mathrm{Bu}\right)_{4}(\mathbf{4})$. For later introduction of a squaramide as the actual linker structure, it was necessary to first implement a terminal amine. For this purpose, compound $\mathbf{5}$ was synthesized via amide coupling of $N$-Boc-ethylenediamine to the carboxylic acid functionality of product 4.

Afterwards, all protective groups were deprotected with trifluoroacetic acid and finally squaric acid diethyl ester was coupled to the primary amine at $\mathrm{pH} 7$ to yield the final product AAZTA ${ }^{5}-\mathrm{SA}(6, \mathrm{Fig} .3)$. A severe $\mathrm{pH}$ control is required to prevent double amidation of the squaric acid, which occurs at more basic conditions. Furthermore, for comparison of the two chelator systems, squaric acid diethyl ester was 
coupled analogously to previously deprotected commercially available DOTA $\left({ }^{t} \mathrm{Bu}\right)_{3}$-ethylenediamine. Both bifunctional chelator systems 6 and 7 were purified via HPLC.

\section{Radiolabeling Of AAAZTA 5 -SA And DOTA-SA With ${ }^{177} \mathrm{Lu}$}

Prior to their conjugation to an antibody, AAZTA 5 -SA and DOTA-SA were evaluated for their radiolabeling properties with lutetium-177 as stand-alone bifunctional chelators. For this purpose, $10 \mathrm{nmol}$ of the corresponding compound were incubated with $\left[{ }^{177} \mathrm{Lu}\right] \mathrm{LuCl}_{3}$ in $\mathrm{HEPES}$-buffer at $\mathrm{pH} 7$ and either room temperature or $37^{\circ} \mathrm{C}$. The respective radiochemical yield was analyzed at different times over a period of 30 min via radio-TLC. DOTA-SA showed a negligibly low radiolabeling efficiency at room temperature (0.8 $\pm 0.1 \% \mathrm{RCY}$ ) and even at $37^{\circ} \mathrm{C}$ only a slightly increased radiochemical yield could be obtained after 30 minutes $(6.9 \pm 1.9 \% \mathrm{RCY})$. In contrast, a significantly higher radiochemical yield could be observed for AAZTA ${ }^{5}$-SA at room temperature as well as at $37^{\circ} \mathrm{C}$ after just $1 \mathrm{~min}$. At room temperature, a value of 68.1 $\pm 1.0 \%$ was achieved after $5 \mathrm{~min}$, which did not change considerably in the further process of the reaction $(69.6 \pm 1.4 \%$ after $30 \mathrm{~min})$. At $37^{\circ} \mathrm{C}$ this maximum $(69.6 \pm 0.6 \%)$ could already be reached after $3 \mathrm{~min}$. As shown in Fig. 4A, analysis of the radio-TLC indicated the presence of another not further investigated radiolabeled species with a $R_{f}$ value of 0.4 besides the desired [ ${ }^{177} \mathrm{Lu}$ ] Lu-AAZTA ${ }^{5}-S A$ at $R_{f}=0.1$. It may be assumed that this second species represents either a different protonation stage of the complex or a partially change in conformation or coordination geometry due to the influence of the squaramide linker. Via LC/MS analysis of the bifunctional compound, it was verified that no initial impurity could be responsible for the formation of a second radiolabeled product. Since the ratio of these two species did not change significantly during the reaction, this led to a maximum result of approximately $70 \%$ instead of quantitative radiochemical yields, despite the fact that no unbound radiometal could be observed.

For further analysis, radiolabeling of DOTA-SA was also performed using higher temperatures as well as slightly acidic $\mathrm{pH}$ (5.5). As shown in Fig. 5, at pH 7 (0.5 M HEPES) conditions up to $95{ }^{\circ} \mathrm{C}$ were necessary to produce acceptable radiochemical yields. Similar to the radiolabeling results of AAZTA ${ }^{5}$-SA, a second radiolabeled species could be observed with a proportion of approx. $20 \%$ after 60 min at $95^{\circ} \mathrm{C}$. Since both molecules have a squaramide ester as structural commonality, this might also be an indication for the influence of the squaric acid moiety on the formation of a further species. Utilization of $1 \mathrm{M}$ ammonium acetate buffer ( $\mathrm{pH}$ 5.5) as reaction medium led to significantly faster complexation kinetics and higher radiochemical yields at $95^{\circ} \mathrm{C}$. Already after $30 \mathrm{~min}$ almost no unbound radiometal could be observed. However, these conditions evidently also facilitated the formation of the second radiolabeled species, resulting in a proportion of approx. 45\% after 60 min (Fig. S1).

\section{Antibody Coupling And Radiolabeling Of The Resulting Immunoconjugates}


To evaluate its applicability as a bifunctional chelator system for radiolabeling of temperature and $\mathrm{pH}$ sensitive biomolecules such as antibodies with the therapeutic nuclide ${ }^{177} \mathrm{Lu}$, AAZTA ${ }^{5}$-SA was coupled to bevacizumab as model antibody (Fig. 6). For this purpose, the $\mathrm{pH}$ dependent second amidation of the squaric acid linker was used to form a stable bond between the remaining ethyl ester and lysine side chains of the protein. A tenfold molar excess of AAZTA ${ }^{5}-S A$ resulted in a ratio of $0.29 \pm 0.04$ bound chelator moieties per antibody. This value is sufficiently low to assume the affinity of the antibody not to be affected by the modification. To remove excess unbound chelator molecules from the reaction mixture, the resulting immunoconjugate was purified by fractionated size exclusion chromatography using a gel filtration column and PBS as eluent. Fractions of $0.5 \mathrm{~mL}$ each were collected and then the protein-containing fractions 6 to 8 were combined and used for subsequent ${ }^{177}$ Lu-labeling. Similarly, DOTA-SA was also coupled to bevacizumab and purified under the same conditions. Analogously to the unbound chelator systems, the resulting mAb-conjugates were subsequently incubated with $\left[{ }^{177} \mathrm{Lu}\right] \mathrm{LuCl}_{3}$ in HEPES buffer at $\mathrm{pH} 7$ both at room temperature and at $37^{\circ} \mathrm{C}$.

In the first experiment, ${ }^{177}$ Lu-labeling of the AAZTA ${ }^{5}$-functionalized antibody conjugate resulted in a radiochemical yield of $63.8 \pm 4.3 \%$ at room temperature and $79.3 \pm 3.6 \%$ at $37^{\circ} \mathrm{C}$, respectively. These values were already obtained at the first measured time point after $15 \mathrm{~min}$ and only a small increase could be observed in the further progress of the reaction ( $64.4 \pm 4.2 \%$ and $79.8 \pm 3.3 \%$ after $60 \mathrm{~min})$. In comparison, ${ }^{177}$ Lu-labeling of the DOTA-functionalized analogue indicated a very low radiochemical yield of $2.6 \pm 0.1 \%$ at room temperature after $60 \mathrm{~min}$. At $37{ }^{\circ} \mathrm{C}$, however, the yield increased to $19.5 \pm 1.0 \%$ after the same duration. As expected, this value is significantly lower than that of $\left[{ }^{177} \mathrm{Lu}\right]$ Lu-AAZTA ${ }^{5}-S A-$ bevacizumab, but nevertheless it exceeds the result of unbound DOTA-SA by a factor of almost three.

Analysis of the radio-TLC results of the AAZTA ${ }^{5}$-functionalized conjugate indicated the presence of a radiolabeled sideproduct at $R_{f}=0.1$ and at least one other impurity at $R_{f}=0.4$ besides the desired radioimmunoconjugate at $R_{f}=0$ (Fig. 7B). These species led to a decreased maximum radiochemical yield despite the absence of unbound ${ }^{177}$ Lu but could be removed via subsequent SEC-purification providing a radiochemical purity of $>99 \%$ and an apparent specific activity of $4.5 \mathrm{GBq} / \mu \mathrm{mol}$.

Comparison of the obtained radio-TLC results of the AAZTA ${ }^{5}$-functionalized antibody with those of the unbound chelator led to the assumption that the previous SEC purification was insufficient (Fig. 7B). The $R_{f}$ values of the present impurities match exactly with the $R_{f}$ values of AAZTA ${ }^{5}-S A$ and its second species (0.1 and 0.4).

For a more profound analysis, coupling of AAZTA - -SA to bevacizumab was repeated in a second approach. Instead of combining the protein-containing fractions 6 to 8 after SEC-purification, this time fractions 5 to 10 were used separately for subsequent ${ }^{177}$ Lu-labeling. In this case, identical labeling conditions as previously described were chosen. As shown in Fig. 8, radiolabeling of fraction 5 resulted almost exclusively in free uncomplexed radiometal $\left(R_{f}=0.8-1.0\right)$ indicating the absence of the AAZTA ${ }^{5}$ conjugated antibody as expected. Fraction 6, in contrast, showed a decreasing amount of free ${ }^{177} \mathrm{Lu}$ and 
the desired radiolabeled product $\left(R_{f}=0\right)$ with a progressively increasing radiochemical yield. ${ }^{177} \mathrm{Lu}-$ labeling of fraction 7 indicated the AAZTA ${ }^{5}$-functionalized protein being the main component with an additional impurity of non-separated AAZTA - -SA (approx. 28\%). Furthermore, a small amount of the second species at $R_{f}=0.4$ was also detectable, confirming the presence of excess unbound chelator. Fraction 8 already consisted primarily of AAZTA ${ }^{5}$-SA and only a small amount represented the corresponding immunoconjugate. Finally, labeling of fractions 9 and 10 confirmed the exclusive presence of the unbound bifunctional chelator moiety with increasing elution volume.

Separate radiolabeling of individual fractions after SEC-purification of AAZTA ${ }^{5}$-SA-bevacizumab could therefore confirm the assumption that the excess unbound chelator was not completely separated in the first approach. It could be shown that a certain breakthrough of AAZTA ${ }^{5}$-SA leads to contamination of the antibody-containing fractions even at lower elution volumes than expected.

In order to optimize the purity of the protein solution used for labeling, a further approach for coupling of the bifunctional chelator system to the model antibody bevacizumab and purification was performed. Instead of combining the protein-containing fractions $6-8$, this time only fraction 6 , which provides the highest purity of modified antibody, was used for subsequent ${ }^{177}$ Lu-labeling at room temperature as well as at $37^{\circ} \mathrm{C}$. Fraction 7 , which consists mainly of the required immunoconjugate with a certain impurity of excess unbound chelator (Fig. 8), was further purified via second SEC before radiolabeling. For comparison, antibody functionalization and this extended purification was performed both with AAZTA ${ }^{5}$ SA and DOTA-SA. ${ }^{177}$ Lu-labeling conditions were chosen analogous to the previously described experiments.

Radiolabeling of the 6 th fraction after SEC-purification of AAZTA ${ }^{5}-S A-m A b ~(175-457 \mu$ g protein) resulted after $90 \mathrm{~min}$ in almost quantitative radiochemical yields of $99.2 \pm 0.3 \%$ at room temperature and $99.7 \pm$ $0.1 \%$ at $37^{\circ} \mathrm{C}$, respectively. Already after $10 \mathrm{~min}$ at $37^{\circ} \mathrm{C}$ a radiochemical yield of $92.0 \pm 1.5 \%$ could be obtained. As expected, slightly slower reaction kinetics was observed at room temperature $(86.7 \pm 2.3 \%$ after $15 \mathrm{~min}$ ). However, these results indicate again a very fast complexation of ${ }^{177} \mathrm{Lu}$ at mild temperatures and a neutral pH value by the AAZTA ${ }^{5}$-SA moiety. The twice-purified fraction 7 (199-419 $\mu \mathrm{g}$ protein after second SEC) showed also comparable outcomes of $97.30 \pm 1.8 \%$ at room temperature and $97.90 \pm 0.1 \%$ after $90 \mathrm{~min}$ at $37^{\circ} \mathrm{C}$, respectively using analogous labeling conditions.

In comparison, ${ }^{177}$ Lu-labeling of both fraction 6 (278-382 $\mu$ g protein) and the twice-purified fraction 7 (272-273 $\mu \mathrm{g}$ protein after second SEC) of the DOTA-functionalized immunoconjugate provided only negligible complexation rates at room temperature and $37^{\circ} \mathrm{C}$, confirming the unique advantages of AAZTA $A^{5}$-SA. Here, the obtained results $\left(<2 \% \mathrm{RCY}\right.$ at $\left.37^{\circ} \mathrm{C}\right)$ differ considerably from the first radiolabeling approach of the DOTA-functionalized antibody $(19.5 \pm 1.0 \%)$. This can be explained by different concentrations of the modified protein in the individual experiments. While in the first labeling approach $900 \mu \mathrm{g}$ of the radioimmunoconjugate were used in each case, the optimized purification and separation 
of the fractions in the last approach led to a lower amount per labeling experiment $(272382 \mu \mathrm{g})$ at constant volume.

\section{In vitro complex stability of [ ${ }^{177}$ Lu]Lu-AAZTA ${ }^{5}$-SA-bevacizumab}

The protein-bound ${ }^{177}$ Lu-AAZTA ${ }^{5}$-SA-complex indicated no measurable release of the radiometal in human serum ( $>99 \%$ intact conjugate) over a period of at least 15 days. In PBS the complex remained stable within the first $48 \mathrm{~h}(>99 \%)$ and only a slightly decreased stability could be observed during the following $13 \mathrm{~d}$ resulting in $93.9 \pm 0.9 \%$ intact conjugate (Fig. 10).

\section{Conclusion}

In the present study a novel AAZTA ${ }^{5}$ squaramide ester was synthesized, evaluated and compared to the DOTA-functionalized analogue regarding its applicability as bifunctional chelator for radiolabeling of sensitive biomolecules such as antibodies with the theranostic radiometal lutetium-177 under mild conditions. Prior to evaluation of the corresponding immunoconjugates, the HPLC-purified bifunctional chelators were radiolabeled with ${ }^{177} \mathrm{Lu}$ as stand-alone systems at neutral $\mathrm{pH}$ and both at room temperature and $37{ }^{\circ} \mathrm{C}$. While labeling of DOTA-SA resulted in negligibly low yields $(6.9 \pm 1.9 \%$ RCY after $30 \mathrm{~min})$ even at slightly elevated temperatures $\left(37^{\circ} \mathrm{C}\right),\left[{ }^{177} \mathrm{Lu}\right]$ Lu-AAZTA ${ }^{5}-\mathrm{SA}$ achieved almost $70 \% \mathrm{RCY}$ already after $3 \mathrm{~min}$ at room temperature.

Coupling of AAZTA ${ }^{5}-S A$ to the model antibody bevacizumab resulted in a ratio of $0.29 \pm 0.04$ bound chelator moieties per protein. Purification and ${ }^{177}$ Lu-labeling of the resulting immunoconjugate was evaluated and optimized within three approaches. In the first approach, radiolabeling of the combined protein-containing volumes resulting from fractionated SEC already produced a radiochemical yield of $63.8 \pm 4.3 \%$ at room temperature and $79.3 \pm 3.6 \%$ at $37^{\circ} \mathrm{C}$ after a short reaction time ( $\left.15 \mathrm{~min}\right)$. The DOTA analogue, as expected, showed a significantly lower complexation rate resulting in $2.6 \pm 0.1 \%$ RCY at RT and $19.5 \pm 1.0 \% \mathrm{RCY}$ at $37^{\circ} \mathrm{C}$ after $60 \mathrm{~min}$. Analysis of the radio-TLC results indicated the presence of a certain residue of unbound $A A Z T A^{5}-S A$ leading to a radiolabeled sideproduct and therefore to reduced radiochemical yields of $\left[{ }^{177} \mathrm{Lu}\right] \mathrm{Lu}-\mathrm{AAZTA} \mathrm{A}^{5}-\mathrm{SA}-\mathrm{mAb}$.

In a second approach the individual fractions after SEC-purification of AAZTA ${ }^{5}-S A-m A b$ were radiolabeled with ${ }^{177}$ Lu separately in order to determine the breakthrough of excess unbound AAZTA ${ }^{5}$-SA. It could be confirmed that with increasing elution volume a certain amount of excess unbound chelator is already present in the protein-containing fractions.

Thus, in a further approach, SEC-purification of the AAZTA ${ }^{5}$-modified protein was optimized via separate use of the fraction containing exclusively the corresponding immunoconjugate and via repeated SEC of the fraction containing a certain amount of excess unbound chelator. Subsequent ${ }^{177}$ Lu-labeling successfully confirmed the separation of AAZTA ${ }^{5}$-SA via significantly improved radiochemical yields and purity of $\left[{ }^{177} \mathrm{Lu}\right] \mathrm{Lu}-\mathrm{AAZT} A^{5}-\mathrm{SA}-\mathrm{mAb}$ already after short reaction times of $10-15 \mathrm{~min}\left(>90 \%\right.$ at $37^{\circ} \mathrm{C}$ and 
$>85 \%$ at room temperature, respectively). After approximately $30 \mathrm{~min}$ almost quantitative yields could be achieved for both temperatures. In contrast, the analogously purified DOTA-conjugate provided only negligibly low complexation rates both at room temperature and $37^{\circ} \mathrm{C}$ underlining its disadvantages over the AAZTA ${ }^{5}$ system.

While these labeling studies successfully verified the potency of the AAZTA ${ }^{5}-S A$ moiety for fast and almost quantitative ${ }^{177} \mathrm{Lu}$-coordination, the stability of the protein bound complex was investigated as second aspect. Indeed, [ ${ }^{177}$ Lu] Lu-AAZTA ${ }^{5}$-SA-mAb appeared to be very stable both in human serum and PBS at $37^{\circ} \mathrm{C}$ over a long period of more than two weeks ( $>99 \%$ and $>93 \%$, respectively).

The results of this study show the high potential of the novel AAZTA ${ }^{5}$ squaramide ester as bifunctional chelator system for mild radiolabeling of sensitive target vectors such as antibodies with ${ }^{177} \mathrm{Lu}$. It therefore represents a promising tool for formation of radioimmunoconjugates that can be used for diagnostic and therapeutic applications as well as for simultaneous imaging of the therapeutic progress. Furthermore, we expect these advantages to be also transferable to applications with various other target vectors, e.g. those based on small molecules, peptides or polymeric structures.

\section{List Of Abbrevations}

AAZTA: 1,4-Bis(carboxymethyl)-6-[bis(carboxymethyl)]amino-6-methylperhydro-1,4-diazepine; AAZTA ${ }^{5}$ : 1,4-Bis(carboxymethyl)-6-[bis(carboxymethyl)]amino-6-[pentanoic-acid]perhydro-1,4-diazepine; Boc: tertButyloxycarbonyl protecting group; ${ }^{t} \mathrm{Bu}$ : tert-Butyl protecting group; CAR: Chelator-to-antibody ratio; $\mathrm{CHX}$ A"-DTPA: Cyclohexyldiethylenetriaminepentaacetic acid; DIPEA: $N, N$-Diisopropylethylamine; DMSO: Dimethyl sulfoxide; DOTA: 1,4,7,10-Tetraazacyclododecane-1,4,7,10-tetraacetic acid; DOTAGA: 1,4,7,10Tetraazacyclododececane-1-glutaric acid-4,7,10-triacetic acid; DOTATATE: DOTA-(Tyr ${ }^{3}$ )-octreotate; DOTATOC: (DOTA ${ }^{0}-$ Phe $^{1}-$ Tyr $^{3}$ )octreotide; DTPA: Diethylenetriaminepentaacetic acid; EMA: European Medicines Agency; ESI: Electrospray ionization; EtOH: Ethanol; FDA: Food and Drug Administration; HBTU: 2-(1 H-Benzotriazol-1-yl)-1,1,3,3-tetramethyluronium hexafluorophosphate; HEPES: 4-(2-Hydroxyethyl)-1piperazineethanesulfonic acid; HOBt: Hydroxybenzotriazole; HPLC: High-performance liquid chromatography; LC: Liquid chromatography; mAb: Monoclonal antibody; $\mathrm{MeCN}$ : Acetonitrile; $\mathrm{MeOH}$ : Methanol; MRI: Magnetic resonance imaging; MS: Mass spectrometry; n.c.a.: No-carrier-added; $\mathrm{NH}_{4} \mathrm{OAc}$ : Ammonium acetate; NMR: Nuclear magnetic resonance; PBS: Phosphate buffered saline; PET: Positron emission tomography; RCY: Radiochemical yield; RIT: Radioimmunotherapy; RT: Room temperature; SA: Squaric acid; $\mathrm{SA}(\mathrm{OEt})_{2}$ : Squaric acid diethyl ester; SEC: Size exclusion chromatography; SPECT: Single photon emission computed tomography; TETA: 1,4,8,11-Tetraazacyclotetradecane-1,4,8,11-tetraacetic acid; TFA: Trifluoroacetic acid; TLC: Thin layer chromatography

\section{Declarations}

Ethics approval and consent to participate: Not applicable. 
Consent for publication: Not applicable.

Availability of data and materials: Data sharing is not applicable to this article as no datasets were generated or analysed during the current study.

Competing interests: The authors declare that they have no competing interests.

Funding: No specific funding was received.

Authors contribution: BK planned and conceived the present study and wrote the manuscript. BK and ESM were in charge for organic and radiochemical synthesis and evaluation. FR supervised the whole part of the study. All authors read and approved the manuscript.

Acknowledgements: The authors would like to thank Riem Attariya for measurements of protein concentrations and ITG (Garching, Germany) for the provision of n.c.a. ${ }^{177} \mathrm{Lu}$. The authors are also very grateful to the Collaborative Research Center SFB 1066 of the German Research Foundation (DFG) for its support.

\section{References}

1. Abramowicz D, Schandene L, Goldman M, Crusiaux A, Vereerstraeten P, De Pauw L, et al. Release of tumor necrosis factor, interleukin-2, and gamma-interferon in serum after injection of OKT3 monoclonal antibody in kidney transplant recipients. Transplantation. 1989;47:606-8.

2. Aime S, Calabi L, Cavallotti C, Gianolio E, Giovenzana GB, Losi P, et al. [ Gd-AAZTA ] -: A New Structural Entry for an Improved Generation of MRI Contrast Agents. Inorg Chem. 2004;43(24):758890.

3. Ballangrud ÅM, Yang WH, Palm S, Enmon R, Borchardt PE, Pellegrini VA, et al. Alpha-particle emitting atomic generator (actinium-225)-labeled trastuzumab (Herceptin) targeting of breast cancer spheroids: Efficacy versus HER2/neu expression. Clin Cancer Res. 2004;10(13):4489-97.

4. Banerjee S, Pillai MRA, Knapp FF. Lutetium-177 therapeutic radiopharmaceuticals: Linking chemistry, radiochemistry, and practical applications. Chem Rev. 2015;115(8):2934-74.

5. Baranyai Z, Uggeri F, Giovenzana GB, Bényei A, Brücher E, Aime S. Equilibrium and Kinetic Properties of the Lanthanoids(III) and Various Divalent Metal Complexes of the Heptadentate Ligand AAZTA. Chem Eur J. 2009;15:1696-705.

6. Barbet J, Bardiès $M$, Bourgeois $M$, Chatal J-F, Chérel $M$, Davodeau F, et al Radiolabeled Antibodies for Cancer Imaging and Therapy. In: Chames P, editor. Methods Mol. Biol. 2nd ed. Springer; 2012. p. 681-97.

7. Barbet $J$, Chatal J-F, Kraeber-Bodéré F. Les anticorps radiomarqués pour le traitement des cancers. médecine/sciences. 2009;25(12):1039-45.

8. Blower PJ, Lewis JS, Zweit J. Copper radionuclides and radiopharmaceuticals in nuclear medicine. Nucl Med Biol. 1996;23(8):957-80. 
9. Bodei L, Kidd M, Prasad V, Modlin IM. Peptide Receptor Radionuclide Therapy of Neuroendocrine Tumors. Front Horm Res. 2015;44:198-215.

10. Bohdiewicz PJ. Indium-111 satumomab pendetide: The first FDA-approved monoclonal antibody for tumor imaging. J Nucl Med Technol. 1998;26(3):155-63.

11. Boros E, Holland JP. Chemical aspects of metal ion chelation in the synthesis and application antibody-based radiotracers. J Label Compd Radiopharm. 2018;61(9):652-71.

12. Boswell CA, Brechbiel MW. Development of radioimmunotherapeutic and diagnostic antibodies: an inside-out view. Nucl Med Biol. 2007;34(7):757-78.

13. Breeman WAP, De Jong M, Visser TJ, Erion JL, Krenning EP. Optimising conditions for radiolabelling of DOTA-peptides with ${ }^{90} \mathrm{Y},{ }^{111} \mathrm{In}$ and ${ }^{177} \mathrm{Lu}$ at high specific activities. Eur $\mathrm{J}$ Nucl Med Mol Imaging. 2003;30(6):917-20.

14. Breitz HB, Tyler A, Bjorn MJ, Lesley T, Weiden PL. Clinical Experience With Tc-99m Nofetumomab Merpentan (Verluma) Radioimmunoscintigraphy. Clin Nucl Med. 1997;22(9):615-20.

15. Broan CJ, Cox JPL, Craig AS, Kataky R, Parker D, Harrison A, et al. Structure and solution stability of indium and gallium complexes of 1,4,7-triazacyclononanetriacetate and of yttrium complexes of 1,4,7,10-tetraazacyclododecanetetraacetate and related ligands: kinetically stable complexes for use in imaging and radioimmu. J Chem Soc Perkin Trans 2. 1991;53(1):87.

16. Cai HH. Risk Evaluation and Mitigation Strategy for Approved Therapeutic Antibodies. MOJ Immunol. 2014;1(5).

17. Cai HH. Therapeutic Monoclonal Antibodies Approved by FDA in 2015. MOJ Immunol. 2016;3(2).

18. Cai HH. Therapeutic Monoclonal Antibodies Approved by FDA in 2016. MOJ Immunol. 2017;5(1).

19. Cai HH. Therapeutic monoclonal antibodies approved by FDA in 2017. MOJ Immunol. 2018;6(3).

20. Camera L, Kinuya S, Garmestani K, Brechbiel MW, Wu C, Pai LH, et al. Comparative biodistribution of indium- and yttrium-labeled B3 monoclonal antibody conjugated to either 2-(p-SCN-Bz)-6-methylDTPA (1 B4M-DTPA) or 2-(p-SCN-Bz)-1,4,7,10-tetraazacyclododecane tetraacetic acid (2B-DOTA). Eur J Nucl Med. 1994;21(7):640-6.

21. Clarke ET, Martell AE. Stabilities of trivalent metal ion complexes of the tetraacetate derivatives of 12 , 13- and 14-membered tetraazamacrocycles. Inorganica Chim Acta. 1991;190(1):37-46.

22. Dash A, Pillai MRA, Knapp FF. Production of ${ }^{177}$ Lu for Targeted Radionuclide Therapy: Available Options. Nucl Med Mol Imaging. 2015;49(2):85-107.

23. Demirci E, Kabasakal L, Toklu T, Ocak M, Şahin OE, Alan-Selcuk N, et al. ${ }^{177}$ Lu-DOTATATE therapy in patients with neuroendocrine tumours including high-grade (WHO G3) neuroendocrine tumours: Response to treatment and long-term survival update. Nucl Med Commun. 2018;39(8):789-96.

24. Forrer F, Uusijärvi H, Storch D, Maecke HR, Mueller-Brand J. Treatment with ${ }^{177}$ Lu-DOTATOC of patients with relapse of neuroendocrine tumors after treatment with ${ }^{90} \mathrm{Y}$-DOTATOC. J Nucl Med. 2005;46(8):1310-6. 
25. Fortin MA, Orlova A, Malmström PU, Tolmachev V. Labelling chemistry and characterization of ${ }^{90} \mathrm{Y} /$

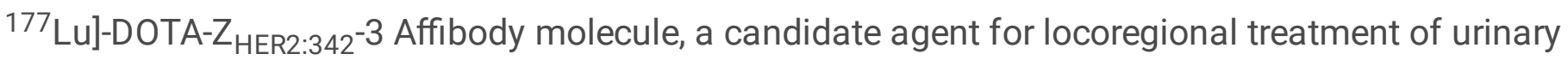
bladder carcinoma. Int J Mol Med. 2007;19(2):285-91.

26. Garrison WM. Reaction Mechanisms in the Radiolysis of Peptides, Polypeptides, and Proteins. Chem Rev. 1987;87(2):381-98.

27. Greifenstein L, Grus T, Nagel J, Sinnes JP, Rösch F. Synthesis and labeling of a squaric acid containing PSMA-inhibitor coupled to AAZTA ${ }^{5}$ for versatile labeling with ${ }^{44} \mathrm{Sc},{ }^{64} \mathrm{Cu},{ }^{68} \mathrm{Ga}$ and ${ }^{177} \mathrm{Lu}$. Appl Radiat Isot. 2020;156:108867.

28. Hens M, Vaidyanathan G, Zhao XG, Bigner DD, Zalutsky MR. Anti-EGFRvIll monoclonal antibody armed with ${ }^{177} \mathrm{Lu}$ : In vivo comparison of macrocyclic and acyclic ligands. Nucl Med Biol. 2010;37(7):741-50.

29. Hermanto S, Haryuni RD, Ramli M, Mutalib A, Hudiyono S. Synthesis and stability test of radioimmunoconjugate ${ }^{177}$ Lu-DOTA-F $\left(a b^{\prime}\right)_{2}$-trastuzumab for theranostic agent of HER2 positive breast cancer. J Radiat Res Appl Sci. 2016;9(4):441-8.

30. Kaplon H, Muralidharan M, Schneider Z, Reichert JM. Antibodies to watch in 2020. MAbs. 2020;12(1).

31. Kasi PM, Sharma A, Jain MK. Expanding the Indication for Novel Theranostic ${ }^{177}$ Lu-Dotatate Peptide Receptor Radionuclide Therapy: Proof-of-Concept of PRRT in Merkel Cell Cancer. Case Rep Oncol. 2019;12(1):98-103.

32. Kawashima H. Radioimmunotherapy. A Specific Treatment Protocol for Cancer by Cytotoxic Radioisotopes Conjugated to Antibodies. Sci World J. 2014;2014:1-10.

33. Kimiz-Gebologlu I, Gulce-lz S, Biray-Avci C. Monoclonal antibodies in cancer immunotherapy. Mol Biol Rep. 2018;45(6):2935-40.

34. Kodama M, Koike T, Mahatma AB, Kimura E. Thermodynamic and Kinetic Studies of Lanthanide Complexes of 1,4,7,10,13-Pentaazacyclopentadecane- $N, N, N^{\prime}, N^{\prime \prime}, N^{\prime \prime \prime}-$ pentaacetic Acid and 1,4,7,10,13,16-Hexaazacyclooctadecane- $N, N, N^{\prime \prime}, N^{\prime \prime}, N^{\prime \prime \prime}, N^{\prime \prime \prime \prime}-$ hexaacetic Acid. Inorg Chem. 1991;30(6):1270-3.

35. Koppe MJ, Bleichrodt RP, Soede AC, Verhofstad AA, Goldenberg DM, Oyen WJG, et al. Biodistribution and therapeutic efficacy of ${ }^{125} /{ }^{131} \mathrm{I}$-, ${ }^{186} \mathrm{Re}-,{ }^{88} /{ }^{90} \mathrm{Y}$-, or ${ }^{177} \mathrm{Lu}$-labeled monoclonal antibody MN-14 to carcinoembryonic antigen in mice with small peritoneal metastases of colorectal origin. J Nucl Med. 2004;45(7):1224-32.

36. Lattuada L, Barge A, Cravotto G, Giovenzana GB, Tei L. The synthesis and application of polyamino polycarboxylic bifunctional chelating agents. Chem Soc Rev. 2011;40(5):3019-49.

37. Liu S, Pietryka J, Ellars CE, Edwards DS. Comparison of Yttrium and Indium complexes of DOTA-BA and DOTA-MBA: Models for ${ }^{90} \mathrm{Y}$ - and ${ }^{111} \mathrm{In}$-labeled DOTA-biomolecule conjugates. Bioconjug Chem. 2002;13(4):902-13.

38. Manzoni L, Belvisi L, Arosio D, Bartolomeo MP, Bianchi A, Brioschi C, et al. Synthesis of Gd and ${ }^{68} \mathrm{Ga}$ Complexes in Conjugation with a Conformationally Optimized RGD Sequence as Potential MRI and 
PET Tumor-Imaging Probes. ChemMedChem. 2012;7(6):1084-93.

39. Milenic DE, Garmestani K, Chappell LL, Dadachova E, Yordanov A, Ma D, et al. In vivo comparison of macrocyclic and acyclic ligands for radiolabeling of monoclonal antibodies with ${ }^{177} \mathrm{Lu}$ for radioimmunotherapeutic applications. Nucl Med Biol. 2002;29(4):431-42.

40. Moek KL, Giesen D, Kok IC, de Groot DJA, Jalving M, Fehrmann RSN, et al. Theranostics Using Antibodies and Antibody-Related Therapeutics. J. Nucl. Med. 2017 Sep 1;58(Suppl 2):83S-90S.

41. Moffat FL, Pinsky CM, Hammershaimb L, Petrelli NJ, Patt YZ, Whaley FS, et al. Clinical utility of external immunoscintigraphy with the IMMU-4 technetium-99m Fab' antibody fragment in patients undergoing surgery for carcinoma of the colon and rectum: Results of a pivotal, phase III trial. J Clin Oncol. 1996;14(8):2295-305.

42. Mullard A. 2018 FDA drug approvals. Nat Rev. 2019;18:85-9.

43. Nagy G, Szikra D, Trencsényi G, Fekete A, Garai I, Giani AM, et al. AAZTA: An Ideal Chelating Agent for the Development of ${ }^{44}$ Sc PET Imaging Agents. Angew Chemie Int Ed. 2017;56(8):2118-22.

44. Orlova A, Jonsson A, Rosik D, Lundqvist $H$, Lindborg $M$, Abrahmsen L, et al. Site-specific radiometal labeling and improved biodistribution using ABY-027, a novel HER2-targeting affibody moleculealbumin-binding domain fusion protein. J Nucl Med. 2013;54(6):961-8.

45. Perk LR, Visser GWM, Vosjan MJWD, Stigter-Van Walsum M, Tijink BM, Leemans CR, et al. ${ }^{89} \mathrm{Zr}$ as a PET surrogate radioisotope for scouting biodistribution of the therapeutic radiometals ${ }^{90} \mathrm{Y}$ and ${ }^{177} \mathrm{Lu}$ in tumor-bearing nude mice after coupling to the internalizing antibody cetuximab. J Nucl Med. 2005;46(11):1898-906.

46. Pfister J, Summer D, Rangger C, Petrik M, von Guggenberg E, Minazzi P, et al. Influence of a novel, versatile bifunctional chelator on theranostic properties of a minigastrin analogue. EJNMMI Res. 2015;5(1):74.

47. Price EW, Orvig C. Matching chelators to radiometals for radiopharmaceuticals. Chem Soc Rev. 2014;43(1):260-90.

48. Quigley A-M, Gnanasegaran G, Buscombe JR, Hilson AJW. Technetium-99m-Labelled Sulesomab (LeukoScan) in the Evaluation of Soft Tissue Infections. Med Princ Pract. 2008;17(6):447-52.

49. Rasaneh S, Rajabi H, Babaei MH, Johari Daha F. Synthesis and biodistribution studies of ${ }^{177} \mathrm{Lu}-$ trastuzumab as a therapeutic agent in the breast cancer mice model. J Label Compd Radiopharm. 2010;53(9):575-9.

50. Repetto-Llamazares A, Abbas N, Bruland ØS, Dahle J, Larsen RH. Advantage of lutetium-177 versus radioiodine immunoconjugate in targeted radionuclide therapy of B-cell tumors. Anticancer Res. 2014;34(7):3263-9.

51. Richter WS, Ivancevic V, Meller J, Lang O, Le Guludec D, Szilvazi I, et al. ${ }^{99 \mathrm{~m}} \mathrm{Tc}$-besilesomab (Scintimun ${ }^{\circledR}$ ) in peripheral osteomyelitis: Comparison with ${ }^{99 \mathrm{~m}} \mathrm{Tc}$-labelled white blood cells. Eur $\mathrm{J}$ Nucl Med Mol Imaging. 2011;38(5):899-910. 
52. Rizvi T, Deng C, Rehm P. Indium-111 Capromab Pendetide (ProstaScint $®$ ) Demonstrates Renal Cell Carcinoma and Aortocaval Nodal Metastases from Prostate Adenocarcinoma. World J Nucl Med. 2015;14(3):209.

53. Rudd SE, Roselt P, Cullinane C, Hicks RJ, Donnelly PS. A desferrioxamine B squaramide ester for the incorporation of zirconium-89 into antibodies. Chem Commun Royal Society of Chemistry. 2016;52(80):11889-92.

54. Sharkey RM, Goldenberg DM. Cancer radioimmunotherapy. Immunotherapy. 2011;3(3):349-70.

55. Sinnes J, Nagel J, Rösch F. AAZTA ${ }^{5} / A A Z T A^{5}-T O C$ : synthesis and radiochemical evaluation with ${ }^{68} \mathrm{Ga}$ ${ }^{44}$ Sc and ${ }^{177}$ Lu. EJNMMI Radiopharm Chem. 2019;4(1):18.

56. Stein R, Govindan SV, Mattes MJ, Chen S, Reed L, Newsome G, et al. Improved iodine radiolabels for monoclonal antibody therapy. Cancer Res. 2003;63(1):111-8.

57. Stimmel JB, Kull FC. Samarium-153 and Lutetium-177 chelation properties of selected macrocyclic and acyclic ligands. Nucl Med Biol. 1998;25(2):117-25.

58. Stimmel JB, Stockstill ME, Kull FC. Yttrium-90 Chelation Properties of Tetraazatetraacetic Acid Macrocycles, Diethylenetriaminepentaacetic Acid Analogs, and a Novel Terpyridine Acyclic Chelator. Bioconjug Chem. 1995;6(2):219-25.

59. Taneja SS. ProstaScint(R) Scan: Contemporary Use in Clinical Practice. Rev Urol. 2004;6(Suppl 10):19-28.

60. Thakral P, Singla S, Yadav MP, Vasisht A, Sharma A, Gupta SK, et al. An approach for conjugation of ${ }^{177}$ Lu- DOTA-SCN- Rituximab (Biosim) \& its evaluation for radioimmunotherapy of relapsed \& refractory B-cell non Hodgkins Lymphoma patients. Indian J Med Res. 2014;139:544-54.

61. Tietze LF, Arlt M, Beller M, Glüsenkamp K, Jähde E, Rajewsky MF. Squaric Acid Diethyl Ester: A New Coupling Reagent for the Formation of Drug Biopolymer Conjugates. Synthesis of Squaric Acid Ester Amides and Diamides. Chem Ber. 1991;124(5):1215-21.

62. Tóth E, Brücher E. Stability constants of the lanthanide(III)-1,4,7,10-tetraazacyclododecane$N, N, N^{\prime \prime}, N^{\prime \prime \prime}$-tetraacetate complexes. Inorganica Chim Acta. 1994;221(1-2):165-7.

63. Waldron BP, Parker D, Burchardt C, Yufit DS, Zimny M, Roesch F. Structure and stability of hexadentate complexes of ligands based on AAZTA for efficient PET labelling with gallium-68. Chem Commun. 2013;49(6):579-81.

64. Wojdowska W, Karczmarczyk U, Maurin M, Garnuszek P, Mikolajczak R. Standardization of Procedures for the Preparation of ${ }^{177} \mathrm{Lu}$ - and ${ }^{90} \mathrm{Y}$-labeled DOTA-Rituximab Based on the Freeze-dried Kit Formulation. Curr Radiopharm. 2015;8(1):62-8.

65. Wurm FR, Klok HA. Be squared: Expanding the horizon of squaric acid-mediated conjugations. Chem Soc Rev. 2013;42(21):8220-36.

66. Yeong $\mathrm{C}$, Cheng $\mathrm{M}, \mathrm{Ng} \mathrm{K}$. Therapeutic radionuclides in nuclear medicine: current and future prospects. J Zhejiang Univ Sci B. 2014;15(10):845-63. 


\section{Additional Files}

Fig. S1: Radiolabeling results of [ $\left.{ }^{177} \mathrm{Lu}\right] \mathrm{Lu}-\mathrm{DOTA}-\mathrm{SA}$ in $1 \mathrm{M} \mathrm{NH}_{4} \mathrm{OAc}$ buffer ( $\mathrm{pH}$ 5.5) at room temperature and $95^{\circ} \mathrm{C}, \mathrm{n}=3$

\section{Figures}

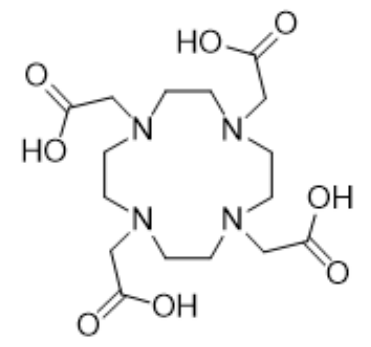

DOTA

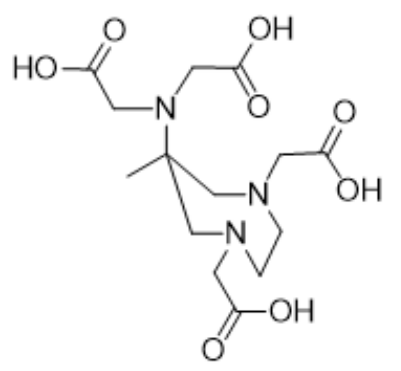

AAZTA

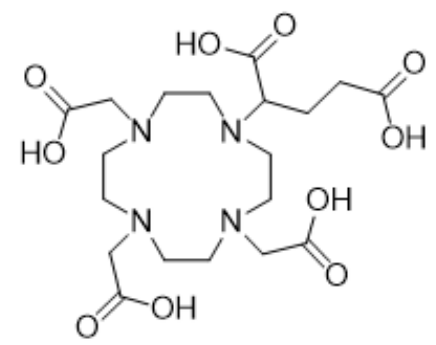

DOTAGA

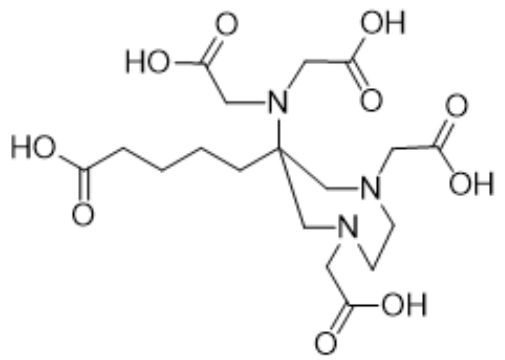

AAZTA $^{5}$

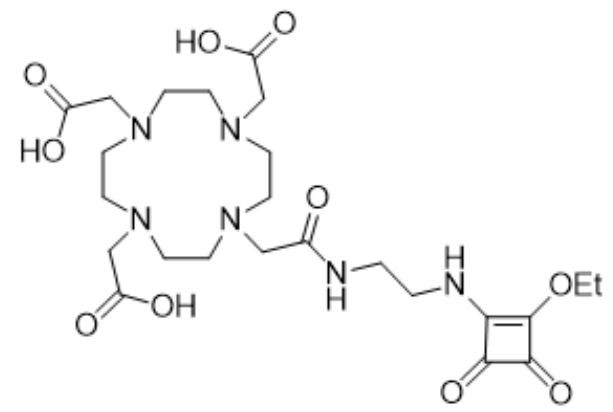

DOTA-SA

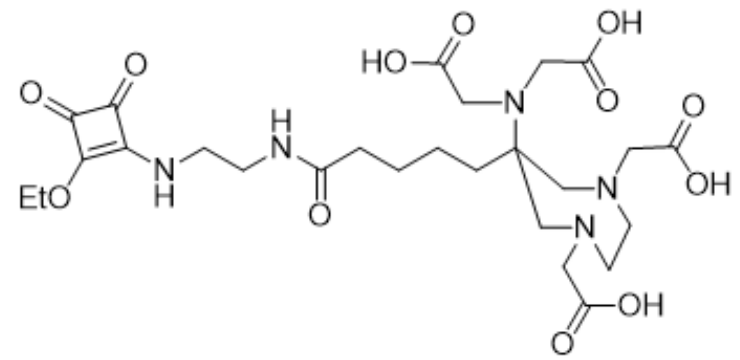

AAZTA ${ }^{5}$-SA

\section{Figure 1}

Basic structures of DOTA, DOTAGA, AAZTA and AAZTA5 as well as the novel DOTA-SA and AAZTA5-SA 


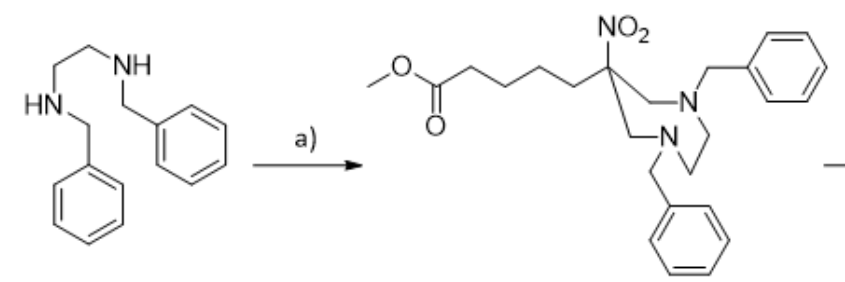

1 b)

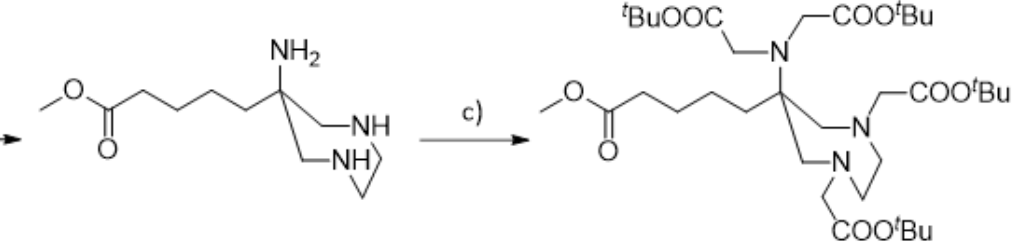

2
3

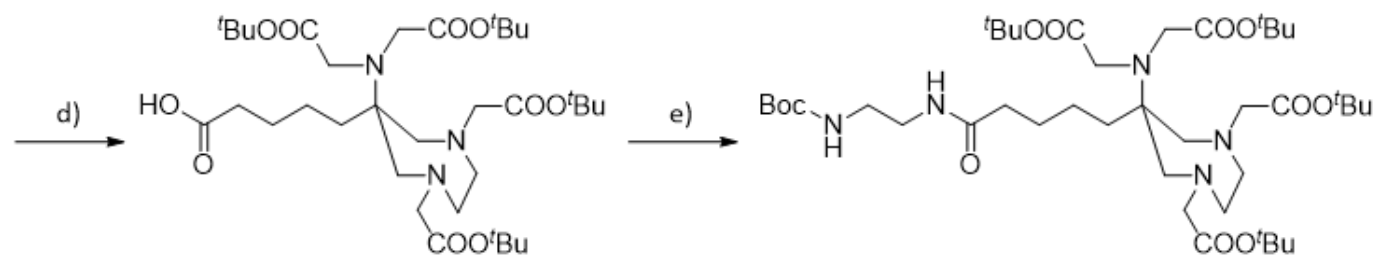

4

5

Figure 2

Schematic overview of the synthesis of protected AAZTA5 and AAZTA5-ethylenediamine: (a) 2nitrocyclohexanone, Amberlyst ${ }^{\circledR}$ A21, paraformaldehyde, $\mathrm{MeOH}, 85 \%$; (b) $\mathrm{Pd}(\mathrm{OH}) 2 / \mathrm{C}, \mathrm{CH} 3 \mathrm{COOH}, \mathrm{H} 2$, EtOH; (c) tert-butyl bromoacetate, K2CO3, KI, MeCN, 54 \%; (d) 1 M LiOH, 1,4-dioxane/H2O (2:1), 69 \%; (e) N-Boc-ethylenediamine, HBTU, HOBt, DIPEA, MeCN, 82\%<smiles>CCOC(=O)CN1CCN(CC(=O)OCC)CC(CCCCC(=O)NCCNC(=O)OCc2ccccc2)(CN(CC(=O)OCC)CC(=O)OCC)C1</smiles>

5<smiles>CCCCOC(=O)CN1CCN(CC(=O)OCC)CCN(CC(=O)OCC)CCN(CC(=O)OCCN)CC1</smiles>

$\stackrel{\text { a) }}{\longrightarrow}$<smiles>CCOc1c(NCCNC(=O)CCCCC2(CN(CC(=O)O)CC(=O)O)CN(CC(=O)O)CCN(CC(=O)O)C2)c(=O)c1=O</smiles>

6

$\stackrel{\text { b) }}{\longrightarrow}$<smiles>CCOc1c(NCCNC(=O)CN2CCN(CC(=O)O)CCN(CC(=O)O)CCN(CC(=O)O)CC2)c(=O)c1=O</smiles> 


\section{Figure 3}

Coupling of squaric acid diethyl ester to AAZTA5-ethylenediamine and DOTA-ethylenediamine to form the corresponding monoamides: (a,b) 1. CH2Cl2/TFA (1:1); 2. 3,4-diethoxycyclobut-3-ene-1,2-dione, phosphate buffer pH 7, a) $29 \%$, b) $41 \%$

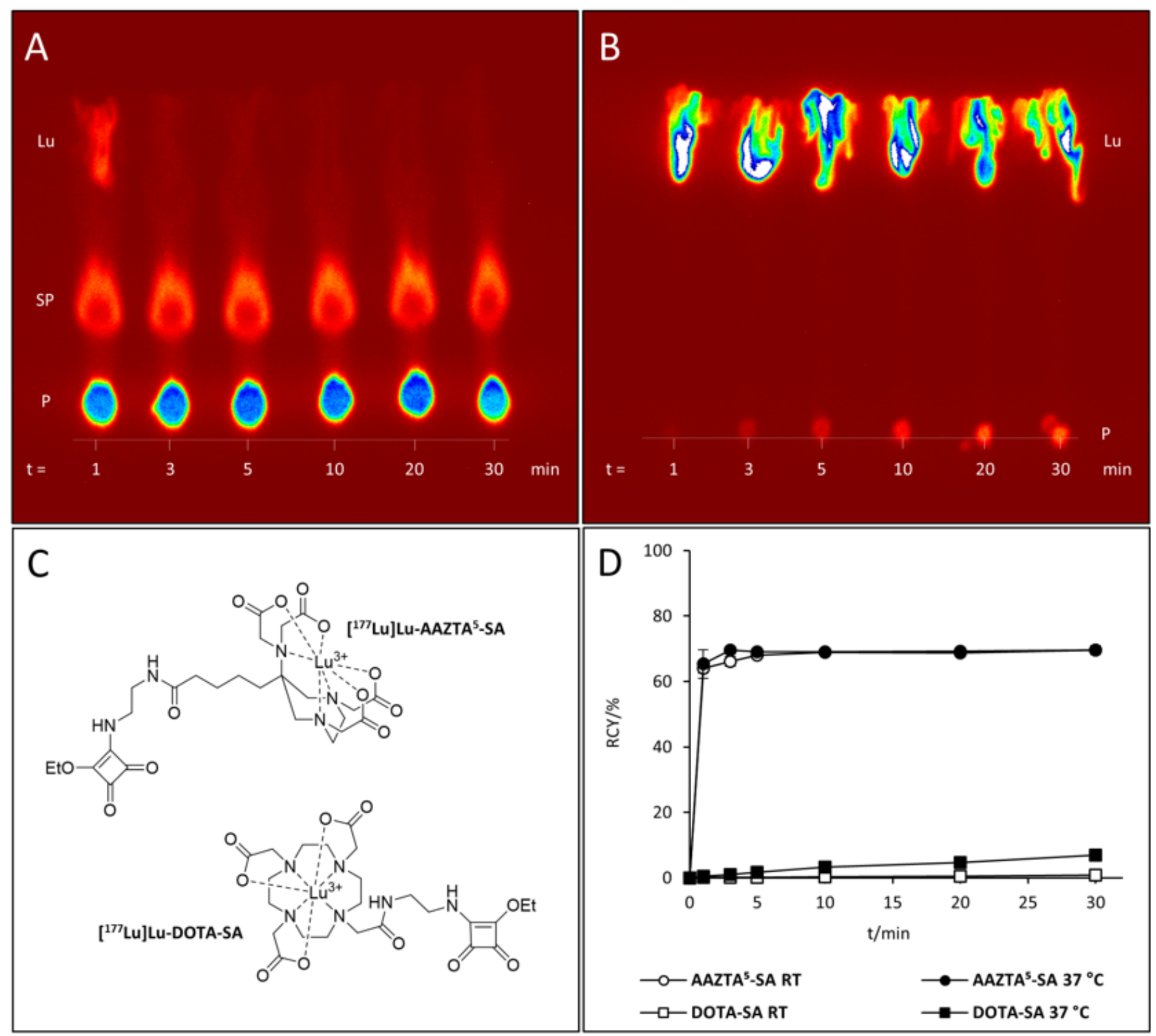

\section{Figure 4}

Evaluation of radiolabeling properties of AAZTA5-SA with 177Lu compared to DOTA-SA: representive radio-TLC images (silica, $0.1 \mathrm{M}$ citrate buffer $\mathrm{pH}$ 4) of the formation of [177Lu]Lu-AAZTA5-SA (A) and [177Lu]Lu-DOTA-SA (B) at $37^{\circ} \mathrm{C}$; coordination structures of the radiolabeled complexes (C); radiolabeling 
kinetics of $10 \mathrm{nmol}$ AAZTA5-SA and $10 \mathrm{~nm}$ DOTA-SA at room temperature and $37^{\circ} \mathrm{C}, \mathrm{n}=3(\mathrm{D}) ; \mathrm{P}=$ product, $\mathrm{SP}=$ sideproduct $/$ second species, $\mathrm{Lu}=$ unbound $177 \mathrm{Lu}$

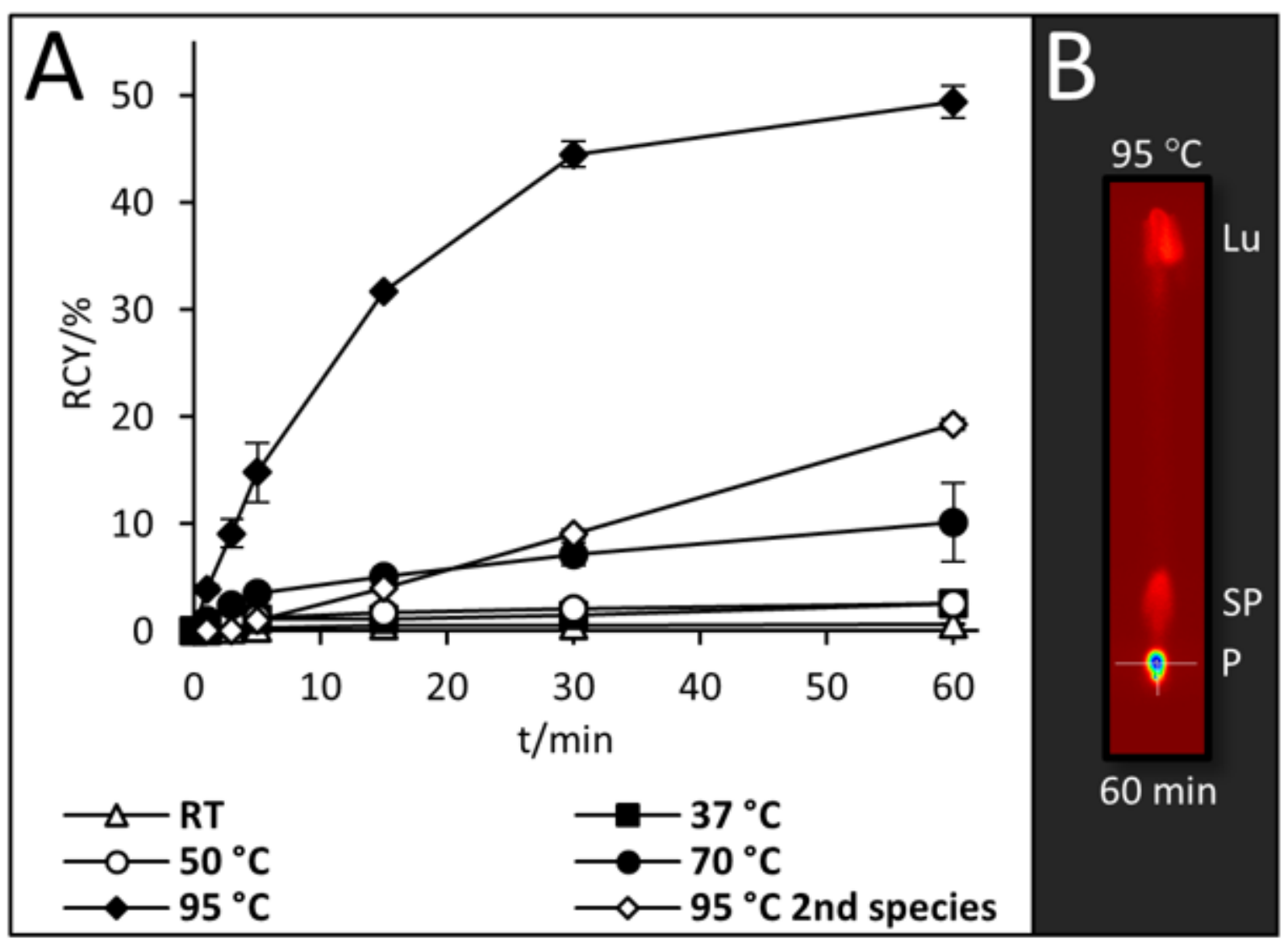

Figure 5

Radiolabeling results of [177Lu]Lu-DOTA-SA in 0.5 M HEPES buffer $(\mathrm{pH} 7)$ using various temperatures, $n$ $=3(\mathrm{~A})$ and a representive radio-TLC image of the results after $60 \mathrm{~min}$ at $95^{\circ} \mathrm{C}(\mathrm{B}) ; \mathrm{P}=$ product, $\mathrm{SP}=$ sideproduct/second species, Lu = unbound $177 \mathrm{Lu}$ 


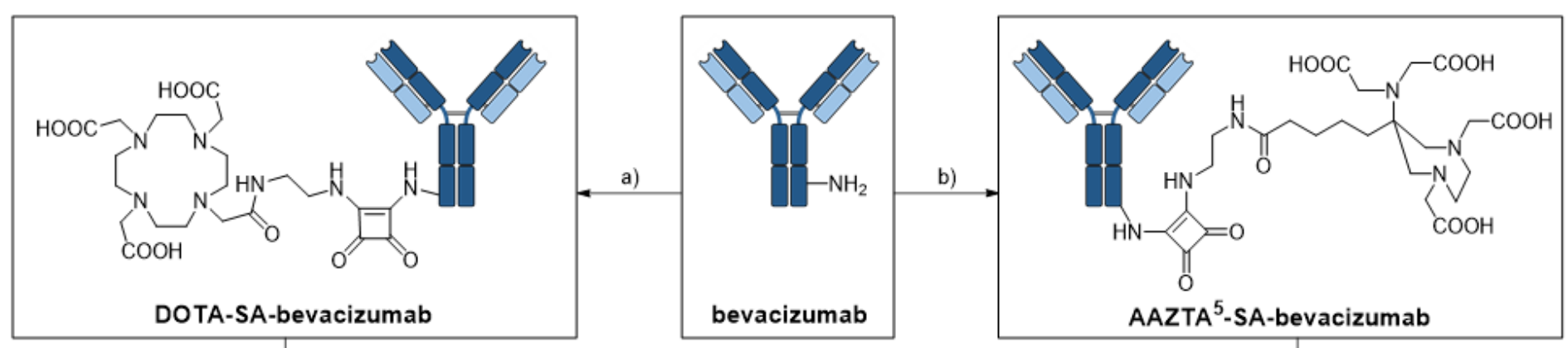

c)

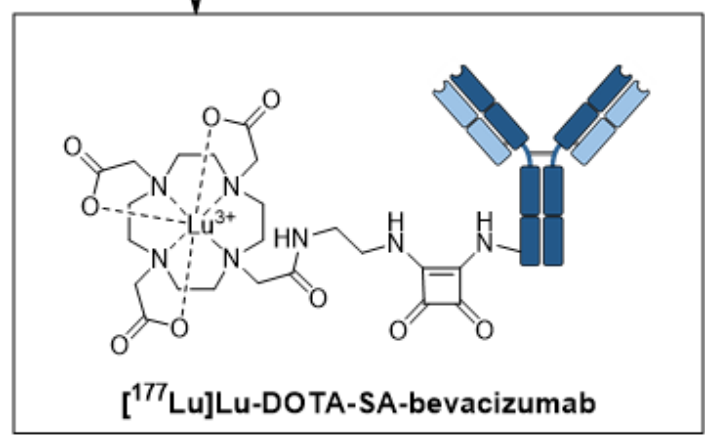

c)

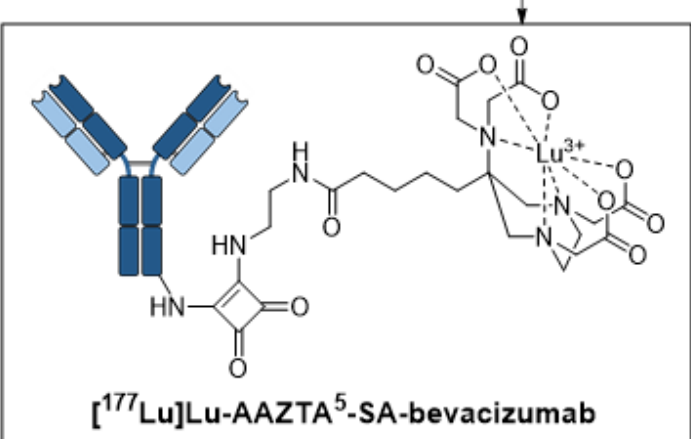

Figure 6

Synthesis and 177Lu-labeling of AAZTA5-SA-mAb and DOTA-SA-mAb: (a) 10 eq. DOTA-SA, phosphate buffer $\mathrm{pH}$ 9; (b) 10 eq. AAZTA5-SA, phosphate buffer pH 9; (c) [177Lu]LuCl3, HEPES buffer pH 7, room temperature or $37^{\circ} \mathrm{C}$

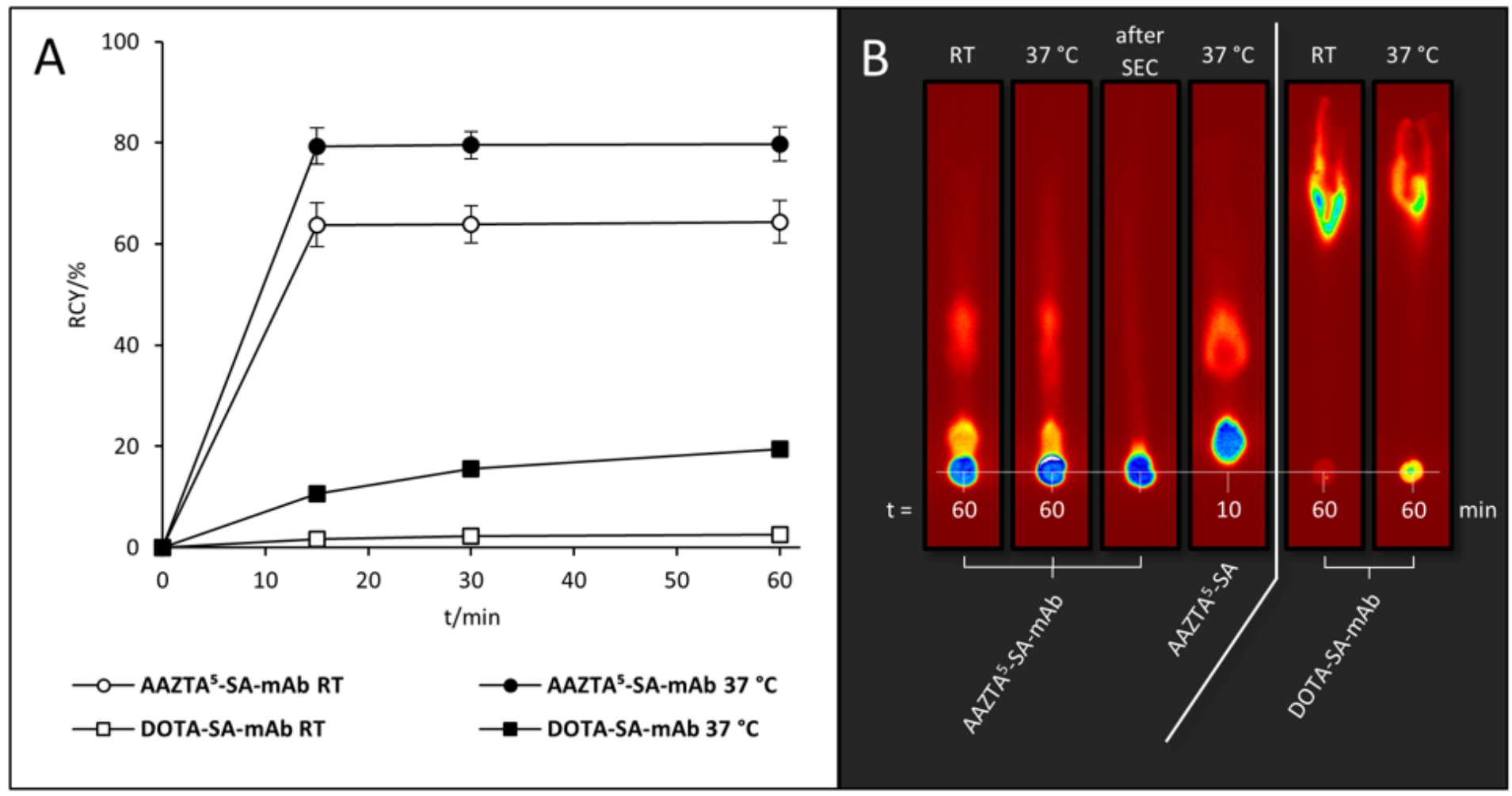




\section{Figure 7}

Radiolabeling efficiency of [177Lu]Lu-AAZTA5-SA-mAb and [177Lu]Lu-DOTA-SA-mAb at room temperature and $37^{\circ} \mathrm{C}, \mathrm{n}=3(\mathrm{~A})$; representive radio-TLC images of the formation of [177Lu]Lu-AAZTA5SA-mAb and [177Lu]Lu-DOTA-SA-mAb after $60 \mathrm{~min}$, unbound [177Lu]Lu-AAZTA5-SA for comparison and purity of [177Lu]Lu-AAZTA5-SA-mAb after SEC (B)

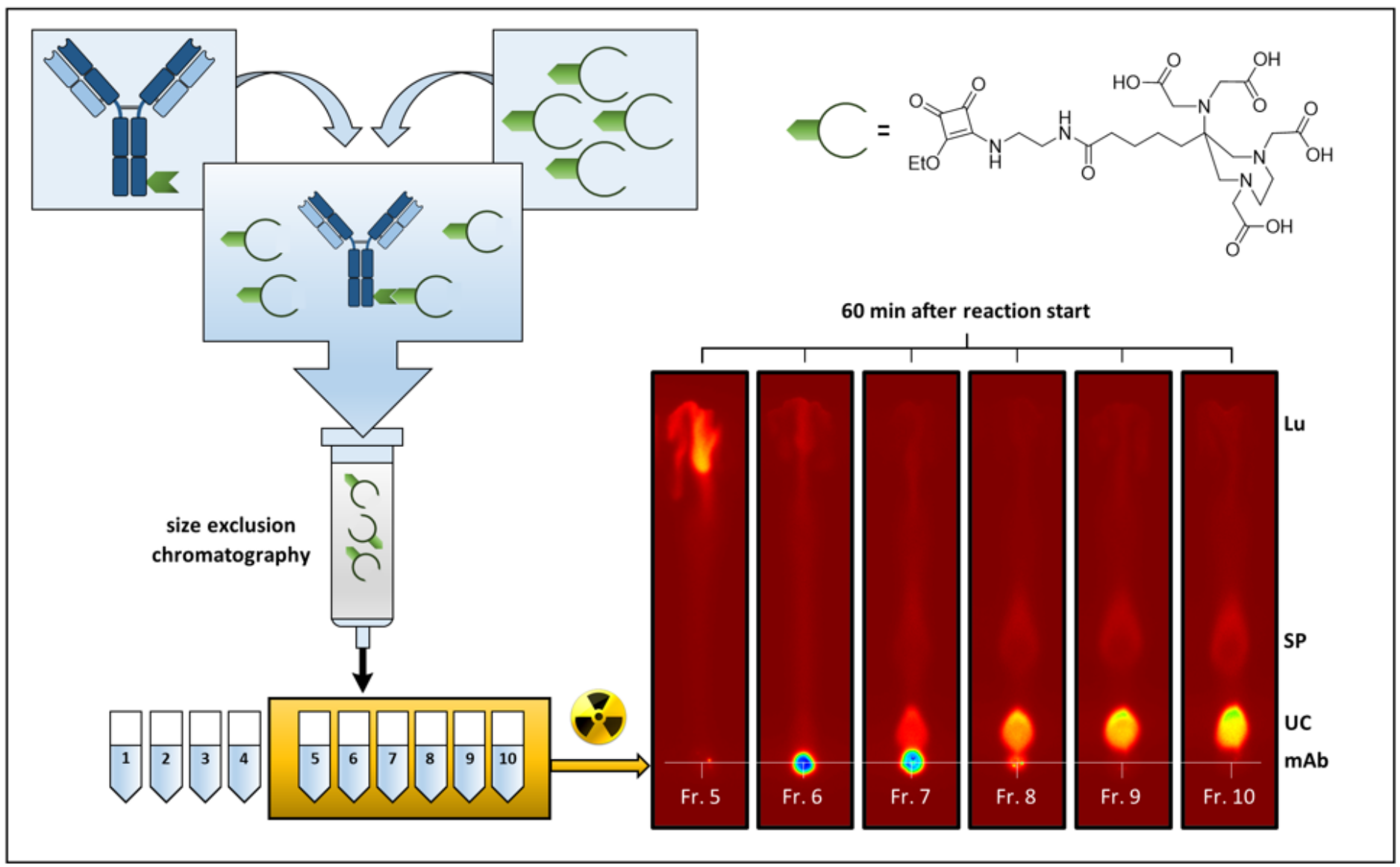

Figure 8

Schematic overview and representive radio-TLC results of 177Lu-labeling of individual fractions after SEC-purification of AAZTA5-SA-bevacizumab (60 min after reaction start); mAb = radiolabeled AAZTA5SA-mAb, UC = radiolabeled excess unbound AAZTA5-SA chelator, SP = radiolabeled side product/second species resulting from unbound chelator, $\mathrm{Lu}=$ free 177 Lu 


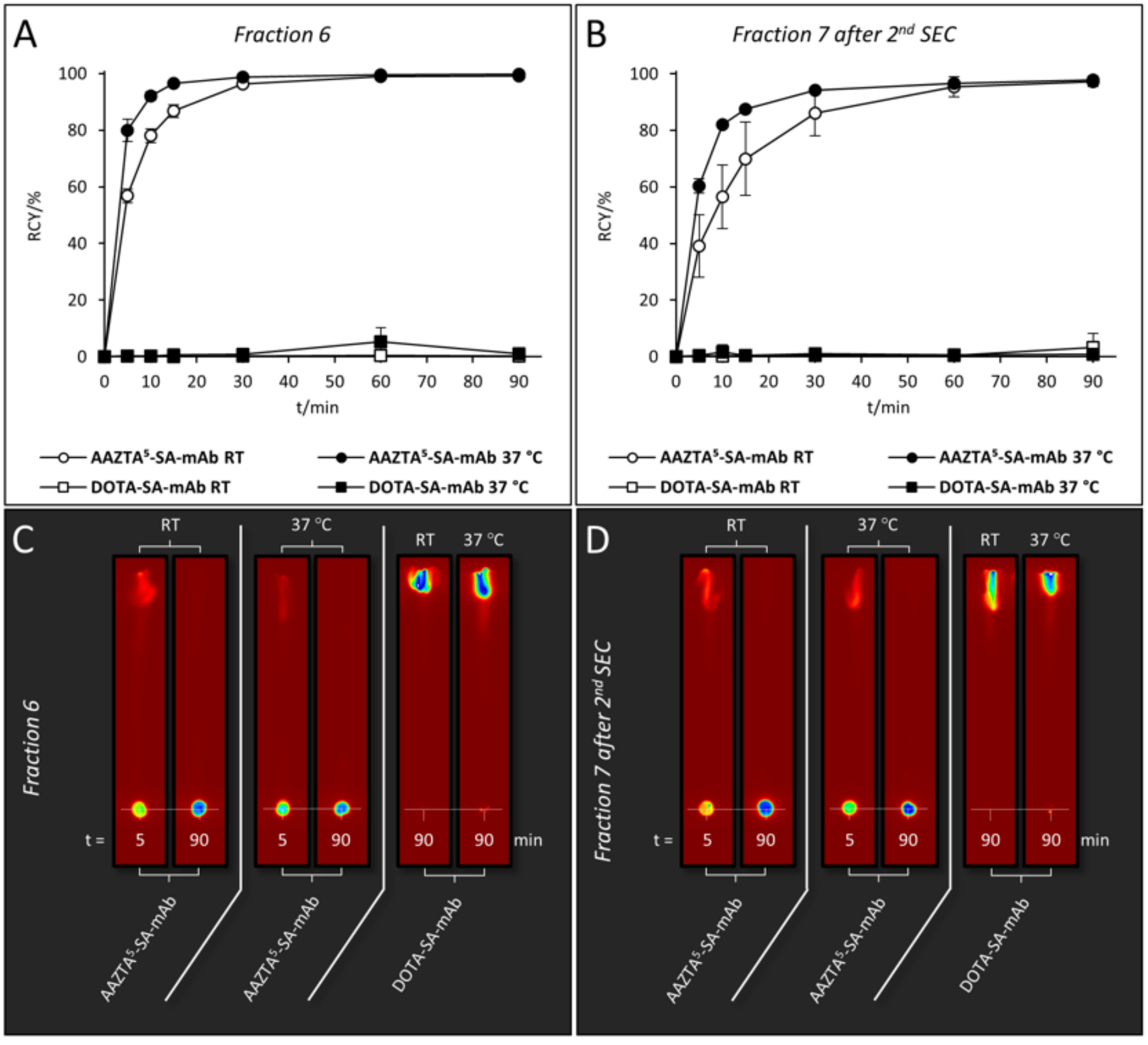

Figure 9

177Lu-labeling results after optimized SEC-purification of AAZTA5-SA-mAb and DOTA-SA-mAb:

Radiolabeling efficiency $(n=3)$ and representive radio-TLC results of the 6th SEC-fraction $(A, C)$ and the twice SEC-purified fraction 7 (B,D) 


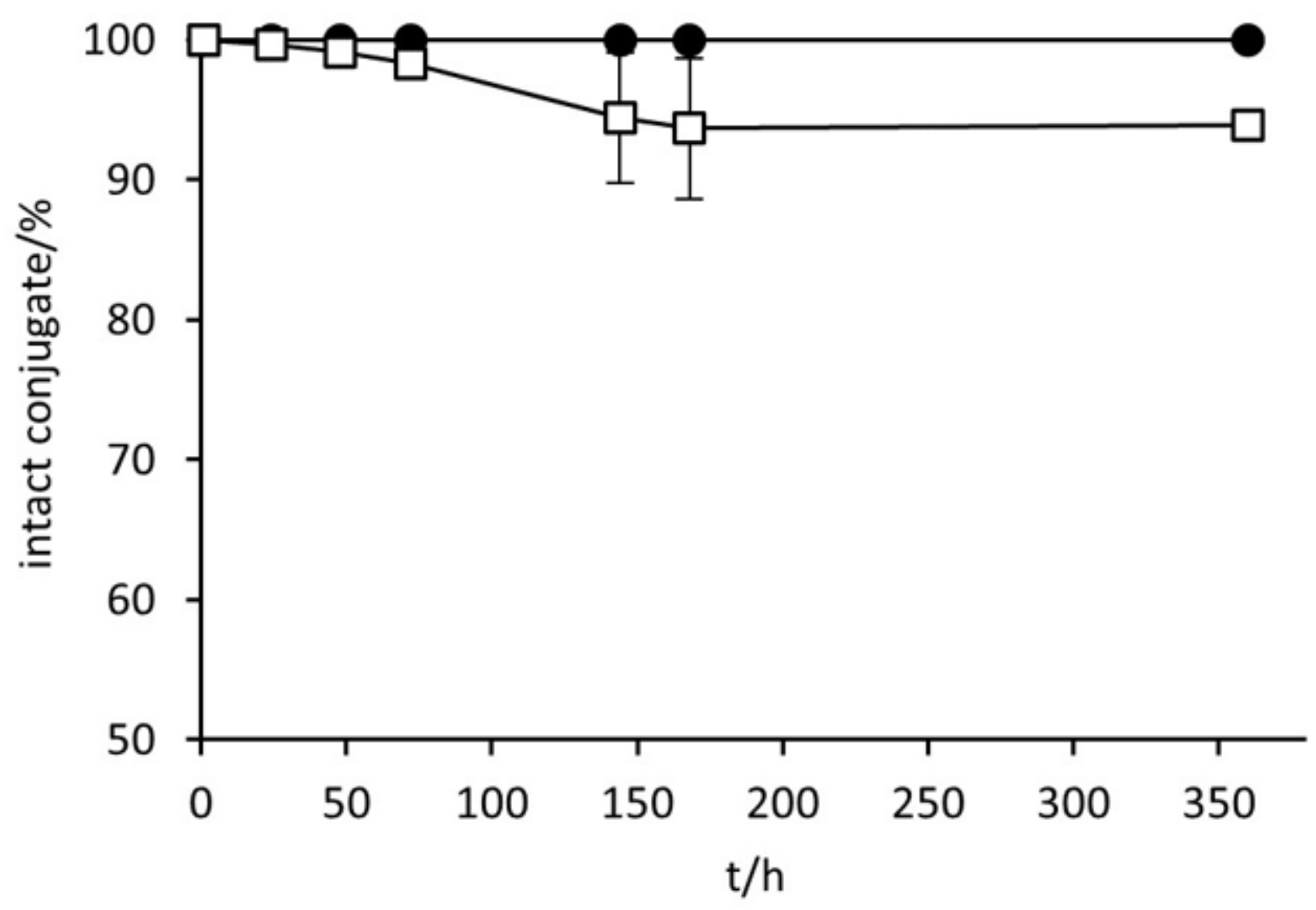

$\longrightarrow$ human serum $\longrightarrow$ - PBS

Figure 10

In vitro complex stability of [177Lu]Lu-AAZTA5-SA-mAb in human serum and PBS within $15 \mathrm{~d}, \mathrm{n}=3$

\section{Supplementary Files}

This is a list of supplementary files associated with this preprint. Click to download.

- FigureS1.pptx 